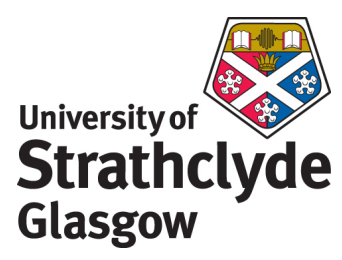

Li, H. and MacKenzie, D. and Hamilton, R. (2010) Parametric finite element studies on the effect of tool shape in friction stir welding. Proceedings of the Institution of Mechanical Engineers, Part B: Journal of Engineering Manufacture, 224 (8). pp. 1161-1173. ISSN 0954-4054

http://strathprints.strath.ac.uk/27456/

Strathprints is designed to allow users to access the research output of the University of Strathclyde. Copyright $(C$ and Moral Rights for the papers on this site are retained by the individual authors and/or other copyright owners. You may not engage in further distribution of the material for any profitmaking activities or any commercial gain. You may freely distribute both the url (http://strathprints.strath.ac.uk) and the content of this paper for research or study, educational, or not-for-profit purposes without prior permission or charge. You may freely distribute the url (http://strathprints.strath.ac.uk) of the Strathprints website.

Any correspondence concerning this service should be sent to The Strathprints Administrator: eprints@cis.strath.ac.uk 


\title{
Parametric Finite Element Studies on the Effect of Tool Shape in Friction Stir Welding
}

\author{
Hongjun Li, Donald Mackenzie and Robert Hamilton ${ }^{1}$ \\ Department of Mechanical Engineering \\ University of Strathclyde \\ James Weir Building \\ 75 Montrose Street \\ Glasgow, UK, G1 1XJ
}

\begin{abstract}
The success of the Friction Stir Welding (FSW) process, and the weld quality produced, depends significantly on the design of the welding tool. In this paper the effect of variation in various tool geometry parameters on FSW process outcomes, during the plunge stage, were investigated. Specifically the tool shoulder surface angle and the ratio of the shoulder radius to pin radius on tool reaction force, tool torque, heat generation, temperature distribution and size of the weld zone were investigated. The studies were carried out numerically using the finite element method. The welding process used AA2024 aluminium alloy plates with a thickness of $3 \mathrm{~mm}$. It was found that, in plunge stage, the larger the pin radius the higher force and torque the tool experiences and the greater heat generated. It is also found that the shoulder angle has very little effect on energy dissipation as well as little effect on temperature distribution.
\end{abstract}

\footnotetext{
${ }^{1}$ Corresponding author, Tel.: +44 (0) 141548 2046; Fax: +44 (0) 141552 5105; Email:

r.hamilton@strath.ac.uk
} 


\section{List of Tables}

Table 1 Typical tool geometries used in the literature.

\section{List of Figures}

Figure 1 Illustration of the friction stir welding process.

Figure 2 Tool design used for tool shape study.

Figure 3 The FE mesh for studying the effect of tool shape.

Figure 4 Plots of tool reaction force against time in plunge stage, $\alpha_{\text {tool }}=0^{\circ}$, for $R_{p i n}=1,1.5$, 2 and $2.5 \mathrm{~mm}$.

Figure 5 Plots of tool reaction force against time in plunge stage, $\alpha_{\text {tool }}=2^{\circ}$, for $R_{\text {pin }}=1,1.5$, 2 and $2.5 \mathrm{~mm}$

Figure 6 Plots of tool reaction force against time in plunge stage, $\alpha_{\text {tool }}=5^{\circ}$, for $R_{p i n}=1,1.5$, 2 and $2.5 \mathrm{~mm}$

Figure 7 Plots of tool reaction force against time in plunge stage, $\alpha_{\text {tool }}=8^{\circ}$, for $R_{p i n}=1,1.5$, 2 and $2.5 \mathrm{~mm}$

Figure 8 Plots of tool reaction force against time in plunge stage, $\alpha_{\text {tool }}=10^{\circ}$, for $R_{\text {pin }}=1$, $1.5,2$ and $2.5 \mathrm{~mm}$

Figure 9 Plots of tool reaction force against time in plunge stage, $R_{p i n}=1$, for $\alpha_{\text {tool }}=0^{\circ}$, $\alpha_{\text {tool }}=2^{\circ} \alpha_{\text {tool }}=5^{\circ} \alpha_{\text {tool }}=8^{\circ}$ and $\alpha_{\text {tool }}=10^{\circ}$.

Figure 10 Plots of tool reaction force against time in plunge stage, $R_{p i n}=1.5$, for $\alpha_{\text {tool }}=0^{\circ}$, $\alpha_{\text {tool }}=2^{\circ} \alpha_{\text {tool }}=5^{\circ} \alpha_{\text {tool }}=8^{\circ}$ and $\alpha_{\text {tool }}=10^{\circ}$

Figure 11 Plots of tool reaction force against time in plunge stage, $R_{p i n}=2$, for $\alpha_{\text {tool }}=0^{\circ}$, $\alpha_{\text {tool }}=2^{\circ} \alpha_{\text {tool }}=5^{\circ} \alpha_{\text {tool }}=8^{\circ}$ and $\alpha_{\text {tool }}=10^{\circ}$

Figure 12 Plots of tool reaction force against time in plunge stage, $R_{p i n}=2.5$, for $\alpha_{\text {tool }}=0^{\circ}$, $\alpha_{\text {tool }}=2^{\circ} \alpha_{\text {tool }}=5^{\circ} \alpha_{\text {tool }}=8^{\circ}$ and $\alpha_{\text {tool }}=10^{\circ}$ 
Figure 13 Plots of tool reaction moment against time in plunge stage, (a) $\alpha_{\text {tool }}=0^{\circ}$, (b) $\alpha_{\text {tool }}=2^{\circ}$, (c) $\alpha_{\text {tool }}=5^{\circ}$, (d) $\alpha_{\text {tool }}=8^{\circ}$, (e) $\alpha_{\text {tool }}=10^{\circ}$ for $R_{\text {pin }}=1,1.5,2$ and $2.5 \mathrm{~mm}$.

Figure 14 Plots of tool reaction moment against time in plunge stage, (a) $R_{\text {pin }}=1 \mathrm{~mm}$, (b) $R_{\text {pin }}=15 \mathrm{~mm}$, (c) $R_{\text {pin }}=2 \mathrm{~mm}$, (d) $R_{\text {pin }}=2.5 \mathrm{~mm}$ : for $\alpha_{\text {tool }}=0^{\circ}, \alpha_{\text {tool }}=2^{\circ} \alpha_{\text {tool }}=5^{\circ} \alpha_{\text {tool }}$ $=8^{\circ}$ and $\alpha_{\text {tool }}=10^{\circ}$

Figure 15 plots of frictional dissipation against time in plunge stage, (a) $\alpha_{\text {tool }}=0^{\circ}$, (b) $\alpha_{\text {tool }}$ $=2^{\circ}$, (c) $\alpha_{\text {tool }}=5^{\circ}$, (d) $\alpha_{\text {tool }}=8^{\circ}$, (e) $\alpha_{\text {tool }}=10^{\circ}$ : for $R_{\text {pin }}=1,1.5,2$ and $2.5 \mathrm{~mm}$.

Figure 16 Plots of frictional dissipation against time in plunge stage (a) $R_{\text {pin }}=1 \mathrm{~mm}$, (b) $R_{\text {pin }}=1.5 \mathrm{~mm}$, (c) $R_{\text {pin }}=2 \mathrm{~mm}$, (d) $R_{\text {pin }}=2.5 \mathrm{~mm}$ : for $\alpha_{\text {tool }}=0^{\circ}, 2^{\circ}, 5^{\circ}, 8^{\circ}$ and $10^{\circ}$

Figure 17 Plots of plastic dissipation against time in plunge stage (a) $R_{p i n}=1 \mathrm{~mm}$, (b) $R_{\text {pin }}$ $=1.5 \mathrm{~mm}$, (c) $R_{\text {pin }}=2 \mathrm{~mm}$, (d) $R_{\text {pin }}=2.5 \mathrm{~mm}$ : for $\alpha_{\text {tool }}=0^{\circ}, 2^{\circ}, 5^{\circ}, 8^{\circ}$ and $10^{\circ}$

Figure 18 Plots of plastic dissipation against time in plunge stage, (a) $\alpha_{\text {tool }}=0^{\circ}$, (b) $\alpha_{\text {tool }}$ $=2^{\circ}$, (c) $\alpha_{\text {tool }}=5^{\circ}$, (d) $\alpha_{\text {tool }}=8^{\circ}$, (e) $\alpha_{\text {tool }}=10^{\circ}$ : for $R_{p i n}=1,1.5,2$ and $2.5 \mathrm{~mm}$

Figure 19 Microstructure classification of friction stir welds

Figure 20 Temperature distributions around the tools with $\alpha_{\text {tool }}=0^{\circ}$, when full contact forms in the plunge stage. 


\section{Introduction}

Friction stir welding (FSW) provides a relatively new technique for metal joining and processing, in which a rotating tool, with a particularly designed shape, is first inserted into the adjoining seams of the components to be welded and then travels all along the welding line. The friction stir welding process is illustrated in Figure 1, which has three stages: plunge, dwell and traverse.

The welding tool is the key part of the Friction Stir Welding (FSW) process. It is well known from literature that the shoulder of the tool is the main source of heat generation. It confines the material expulsion and moves the material at the contact interface. The pin is the secondary heat source and its main function is to stir and mix the material from both sides of the joining line. The geometry of both the shoulder and pin has a significant influence on the weld formation, weld quality, and weld mechanical properties and so on.

Extensive studies on the effect of tools were carried out by experiments [1-9]. Hattingh, et.al [4] systematically examined and reported influences of tool geometry factors on weld tensile strength. Six geometric factors were studied: number of flutes, flute angle, flute depth, pin taper angle, pin diameter and thread pitch. The data indicated that the most successful tool designs were likely to incorporate three tapered flutes, a pin diameter taper and have a thread form with a pitch of around $10 \%$ of the pin diameter and perhaps $15 \%$ of the plate thickness.

Elangovan, et. al $[5,6]$ made an attempt to understand the effect of tool pin profile and tool shoulder diameter on the formation of friction stir processing zone in AA6061 and AA2219 aluminium alloys. Five different tool pin profiles (straight cylindrical, tapered cylindrical, threaded cylindrical, triangular and square) with three different shoulder diameters were used to fabricate the joints. From their investigation it was found that the square pin profiled tool produced mechanically sound and metallurgically defect free welds compared to other tool pin profiles.

The effect of the tool pin shape on the mechanical properties and microstructures of 5-mm thick welded aluminum plates was investigated by Fujii, et.al [7] using three different pin shapes: the simplest shape (column without threads), the ordinary shape (column with threads) and the triangular prism shape. It was concluded that for 6061-T6 and 5083-O, the tool shape does not significantly affect the microstructures and mechanical properties of 
the joints and that for aluminum 1050-H24 a columnar tool without threads produces weld with the best mechanical properties. This is because a columnar tool shape induced defects less than the other tools tested.

The effect of different shoulder geometries on the mechanical and microstructural properties of a friction stir welded aluminum 6082 T6 joints were studied by Scialpi, et. al [8]. Three different shoulders with scroll and fillet, cavity and a fillet and only fillet were used. The investigation results showed that, for thin sheets, the best joint has been welded by a shoulder with fillet and cavity.

Boz, et. al [9] investigated the influence of the tool pin design on bonding and mechanical properties in FSW process. For this purpose, five different pins, one of them square crosssectioned and the rest were cylindrical with $0.85,1.10,1.40$ and $2.1 \mathrm{~mm}$ screw pitched were used to carry out welding process. Test results showed that the best bonding was obtained with $0.85 \mathrm{~mm}$ screw pitched stirrer.

Colegrove et al [10] tested three different pin profiles, 'MX-Triflute', plain 'Trivex' and the threaded 'MX-Trivex' with a computational fluid dynamics (CFD) model. The results demonstrated that the profiled probe designs had little effect on the heat input, and the tensile strengths of the welds were comparable.

Buffa [11] used the FE package DEFORM-3D ${ }^{\mathrm{TM}}$ to simulate the full transit FSW process using a visco-plastic material model. The simulation gave a good representation of material flow and strain rates but the deformation history could not be obtained. Material flow in FSW was investigated using a marker insert technique in Seidel and Reynolds[12]. In this experimental method variations in tool geometry and welding parameter were investigated. Chen and Kovacevic [13] used three dimensional FE to study the thermo-mechanical process in aluminium butt welding. This was mainly focussed on predicting the stresses in plates and was validated using the X-ray diffraction technique. Moataz et al [14] found that FSW process parameters such as feed rate and rotational speed had an appreciable effect on abnormal gain growth and tensile properties. In Schmidt et al [15] the material flow in FSW was investigated by various metallography techniques and computer tomography. It was stated in the paper that it was the first attempt in the literature to estimate flow velocities experimentally. 
The friction stir welding process has been investigated further in more recent studies [1619]. In Zhang et al [16] the FE method based on nonlinear continuum mechanics was used to find strain distributions which correlated well with the microstructure zones in the weld. It was also found that there was a quasi-linear relation between the change of axial load on the shoulder and the plastic strain. In Buffa et al [17] the FE method was used to investigate FSW in aluminium. Specifically the welding of sheets of various thicknesses and tools setups were investigated. In Hwang et al [18] various experimental techniques were used to investigate the FSW process. Thermocouples were used to determine temperature histories at various locations on the workpiece, hardness tests were carried out on base metal and heat affected zones and tensile tests were carried out to determine tensile strength. Blignault et al [19] described the design, development and calibration of a rotating transducer which allows measurement of FSW process responses such as forces, energy and temperature.

In the present paper the effect of variation in the tool shoulder surface angle and the ratio of the shoulder radius to pin radius on tool reaction force, tool torque, heat generation, temperature distribution and size of the weld zone during the FSW plunge stage are investigated numerically using finite element method.

The reason for considering only the plunge stage in this study is that this is when the highest and most unstable forces are acting on the tool. Hence during this stage of welding the tool is most likely to experience failure. Another reason is due to the difficulties of modelling the whole process in terms of numerical techniques and computing cost. Specifically these difficulties include the extended computing time for solution and mesh distortion due to large material deformation. Further details of these difficulties and explanations can be found in Li and Mackenzie [20].

\section{FE Model}

A concave conical smooth shoulder surface and a cylindrical pin surface were chosen for current study as shown in Figure 2. There is no standard generally applicable rule for choosing the size and shape of the tool. A collection of typical tool geometries, in the literature [11-15], used for aluminium alloy is shown in Table 1. In these papers, the pin 
height, which varies from $1.5 \mathrm{~mm}$ to $7.9 \mathrm{~mm}$, depends on the required weld depth. The concavity angles, $\alpha_{\text {tool }}$, are in the range of $0^{\circ}-10^{\circ}$. The ratios of the shoulder radius, $R_{\text {shoulder }}$, to the pin radius, $R_{\text {pin }}, R_{\text {shoulder }} / R_{\text {pin }}$ are close to 3 , ranging from 2.6 to 4 .

In the parametric study, Figure 2 shows the tool design utilized, five different shoulder surface angles, $\alpha_{\text {tool }}$ and four different pin radii, $R_{\text {pin }}$ were considered:

$\alpha_{\text {tool }}=0^{\circ}, 2^{\circ}, 5^{\circ}, 8^{\circ}$ and $10^{\circ}$

$R_{\text {pin }}=1 \mathrm{~mm}, 1.5 \mathrm{~mm}, 2 \mathrm{~mm}$ and $2.5 \mathrm{~mm}$

The rest of the geometry parameters, shoulder radius, $R_{\text {shoulder }},(7 \mathrm{~mm})$ and pin height $(2$ $\mathrm{mm})$ were kept constant. All the cases utilized the same procedure and process parameters (rotation speed, $50 \mathrm{rad} / \mathrm{s}$ and plunge speed, $0.25 \mathrm{~mm} / \mathrm{s}$ ). For each shoulder surface angle, $\alpha_{\text {tool}}$, four separate models with different pin radii, $R_{\text {pin }}$ were generated and solved. This gave a total number of twenty different models each taking typically 50 hours to solve on an AMD Opteron Dual Core processor (2.0 Ghz).

The FE mesh of the model is shown in Figure 3, which was specifically designed for simulating the plunge stage, with finer mesh in the stirring region. A single complete plate was used as the workpiece rather than two butted panels to give a continuum model. Aluminium alloy AA2024 material properties were used in the model. The simulation was carried out on ABAQUS/EXPLICIT [21] using an Arbitrary Lagrangian-Eulerian (ALE) formulation which allows the mesh to move independently of the material making it possible to maintain good mesh quality throughout the simulation. The workpiece was modeled using 8-node three dimensional temperature-displacement coupled elements, C3D8RT. The tool and the backing plate were modeled as rigid isothermal surfaces. All the surfaces of the workpiece are assumed to have convection boundary conditions. The bottom surface of the workpiece in contact with backing plate has a convection coefficient of $1000 \mathrm{~W} / \mathrm{m}^{2} \mathrm{~K}$, while the rest surfaces of the workpiece have a much lower convection coefficient, $10 \mathrm{~W} / \mathrm{m}^{2} \mathrm{~K}$. A total of 14000 elements were used in the analysis. A more detailed description of the FSW FE model used for current study was presented in [20]. 


\section{Results and Discussion}

\subsection{Effect of Tool Shape on Tool Reaction Force and Torque}

To look into the effect of the ratio of pin radius, $R_{\text {pin }}$, to shoulder radius, $R_{\text {shoulder }}$, graphs of reaction force against time were plotted for each of the analysis runs, these are shown in Figures 4 to 8 . Readers are reminded that for each case the shoulder radius, $R_{\text {shoulder }}=7 \mathrm{~mm}$. It should be noted, to reduce the computing time, the tool rotating speed and plunging speed were increased to 100 times of their normal value (rotation speed, $50 \mathrm{rad} / \mathrm{s}$ and plunge speed, $0.25 \mathrm{~mm} / \mathrm{s}$ ), i.e. $5000 \mathrm{rad} / \mathrm{s}$ for rotation speed and $25 \mathrm{~mm} / \mathrm{s}$ for plunge speed [20]. Zhang [16] used a similar method but increased speeds by a factor of 1000 times, to reduce solution times.

The maximum scale of the time $\mathrm{X}$-Axis is $8.6 \times 10^{-2} \mathrm{~s}$ or $10.6 \times 10^{-2} \mathrm{~s}$ (in some cases, longer time needed to establish the full contact condition). For the case of $\alpha_{\text {tool }}=0^{\circ}$, i.e. the shoulder has a flat surface, the variation of tool reaction force magnitude with time for four different $R_{\text {pin }}$ values, 1, 1.5, 2 and $2.5 \mathrm{~mm}$ is plotted in Figure 4. At the beginning of the plunge, only the pin was in the contact with the plate. In each of the graphs in Figure 4, the axial force climbed from zero to a relatively stable value at about $0.02 \mathrm{~s}$. After a short time when the shoulder started touching the workpiece, the force was suddenly rising again in a fluctuating manner, then reached the peak value when the tool were in full contact with the plates. It is observed that the larger the pin radius $R_{p i n}$ is, the higher force the tool experiences before the shoulder contacts the plates and the lower peak force during the whole plunge stage. In plunge stage before the shoulder contacts the plates, only the pin is in contact with the workpiece. Hence the larger the pin radius, the larger the pin tip surface area, the larger the contact area, with the same plunge speed, so the higher force the tool experiences. For the tool with a pin radius $R_{p i n}$ of $2.5 \mathrm{~mm}$ there is a relatively smoother transition of force from pin only contact to shoulder contact compared with other smaller radius pins. In particular, the tool that has a $0.1 \mathrm{~mm}$ radius pin carried a reaction force lower than $7 \mathrm{kN}$ before $7.2 \mathrm{~s}$ but the force jumped up to about $57 \mathrm{kN}$ at $8.2 \mathrm{~s}$. Similar characteristics can be found for cases $\alpha_{\text {tool }}=2^{\circ}$ (Fig. 5) and $\alpha_{\text {tool }}=5^{\circ}$ (Fig. 6). While for the case $\alpha_{\text {tool }}=8^{\circ}$ (Fig. 7) all the tools with different pin radius reached a peak reaction force close to each other. Figure 8 shows the curve for $\alpha_{\text {tool }}=10^{\circ}$ with a slightly different trend; the larger pin tool always produces greater force for the whole plunge stage. 
To further examine the effect of the shoulder surface angle, $\alpha_{\text {tool }}$, the graphs of tool reaction force against time were plotted in a different form, as shown in Figures 9 -12. In each figure the pin radius $R_{\text {pin }}$ is fixed and the variation of tool reaction force against time is plotted for five different shoulder surface angle, $\alpha_{\text {tool }}$ values, $0^{\circ}, 2^{\circ}, 5^{\circ}, 8^{\circ}$ and $10^{\circ}$. Again in each figure the shoulder radius, $R_{\text {shoulder }}=7 \mathrm{~mm}$. As expected the shoulder surface angle, $\alpha_{\text {tool }}$ has no effect before the shoulder touches the plates. When the shoulder is in contact with the workpiece, smaller shoulder surface angle tends to give a larger peak reaction force as shown in Figure $9\left(R_{\text {pin }}=1 \mathrm{~mm}\right)$ and Figure $10\left(R_{\text {pin }}=1.5 \mathrm{~mm}\right)$. While for $R_{\text {pin }}=2 \mathrm{~mm}$ (Fig. 11) and $R_{\text {pin }}=2.5 \mathrm{~mm}$ (Fig. 12), similar peak forces were found for all the shoulder angles. It is also observed that the tool with smaller shoulder angle always reaches the peak force value earlier. This is related to the contact surface area when the shoulder is in contact with the workpiece. At the same plunge depth, the smaller the shoulder angle, the more contact area,with the same plunge speed, the earlier the tool reaches the full contact, so the earlier the tool experiences the peak force.

When full contact is established all the curves are expected to approach a similar force magnitude although following different paths. This is because in each analysis, the shoulder radius, $R_{\text {shoulder }}$, is the same and hence the projected area of the tool on horizontal plane is similar too. Therefore the axial force required for a specific sinking depth should be the same theoretically. In fact, for different analyses the temperature and stress distributions were different for the same tool sinking depth during the plunge stage. Hence the tool reaction forces were different as shown in Figures $9-12$. The variation of tool torque with time plots for the purpose of examining the effect of pin radius, $R_{p i n}$, and shoulder surface angle, $\alpha_{\text {tool }}$, is shown in Figure 13 (a-e) and Figure 14 (a-d), respectively. All the curves in these figures demonstrate very similar trends to the curves shown in Figure 4 to 8 and Figure 9 to 12. This is reasonable as the Coulomb friction law was specified in the model. The tool torque therefore is roughly proportional to the tool axial force.

\subsection{Effect of Tool Shape on Heat Generation}

In this section the effect of tool shape on heat generation caused by frictional dissipation and plastic dissipation is evaluated separately. 
The effect of pin radius, $R_{p i n}$, on frictional energy dissipation is illustrated in Figure 15 (ae). In each figure the shoulder angle, $\alpha_{\text {tool }}$, is fixed and the variation of frictional energy dissipation against time is plotted for four different pin radius, $R_{p i n}$, values of $1 \mathrm{~mm}, 1.5 \mathrm{~mm}$, $2 \mathrm{~mm}$ and $2.5 \mathrm{~mm}$. In all the five figures the curves exhibit similar characteristics. It is observed that frictional dissipation increases "bi-linearly" with time. Before the shoulder contacts the plates, the frictional energy dissipation increases linearly with time with different slopes for different pin radii. The larger pin radius tools always provide greater energy increment rates because they have a bigger contact area with the workpiece. It is observed from figure 15 that. When the shoulder is in contact with the workpiece, the frictional dissipation increases in an approximately linear manner but with higher increment rate.

Figure 16 (a-d) shows the plot of frictional dissipation against time to study the effect of shoulder angle, $\alpha_{\text {tool, }}$ when pin radius, $R_{\text {pin }}$, is fixed. It is clear from the figures that all the curves are very close to each other, especially for tools with larger ratio of pin radius to shoulder radius (i.e. Figure $16(\mathrm{c}), R_{p i n}=2$, and Figure $16(\mathrm{~d}), R_{p i n}=2.5$ ). As the pin radius is the same for curves in each figure 16 (a-d), before the shoulder contacts the workpiece, the curves should be similar. After that, there should be difference among curves as indicated in each figure. But for figures 16 (c) and (d) with larger pin radi, the difference is small, this is because the ratio of shoulder surface to pin surface is smaller. The shoulder has a smaller portion of the total contact surface area, so the effect of the variation of heat generated by shoulder surface on the total frictional heat is smaller.

For the plastic energy dissipation, as shown in Figure 17 (a-d), the shoulder surface angle, $\alpha_{\text {tool, }}$ only affects the time at which the turning point on the curves occur. It is observed that as with frictional dissipation, plastic dissipation increases "bi-linearly" with time. After the turning point, regardless of the shoulder surface angle, all the curves in each figure have the very similar plastic energy dissipation increment rate.

The effect of pin radius, $R_{\text {pin }}$, is illustrated in Figure 18 (a-e). The largest amount of plastic dissipation (purple curve) was generated by the tool with the biggest pin radius, $R_{\text {pin }}$ $=2.5 \mathrm{~mm}$ and the smallest amount of plastic dissipation (red curve) corresponds to the smallest pin radius, $R_{p i n}=1 \mathrm{~mm}$. For all the curves, there exists a turning point where the 
curve slope increases suddenly, which may be attributed to the shearing action of the tool shoulder.

The amount of total energy dissipation is mainly dependent on the size of the pin before full contact between the tool and workpiece forms. This is very obvious when only the pin is in contact with workpiece. But once full contact is established, neither the pin radius nor the shoulder surface angle has much effect on the total heat generation.

\subsection{Effect of Tool Shape on Temperature Field and Weld Zone}

As discussed previously, the tool shape determines the nature and balance of heat generation into the workpiece. This has a direct influence on the temperature distribution and consequently weld zone size. Figure 19 illustrates the system of microstructure classification of friction stir welds, accepted by the Friction Stir Welding Licensees Association. This shows a section through the weld zone and tool with the advancing side of tool on the left and retreating side on the right. The scheme partitions the weld zone into four distinct regions: A, unaffected material, B, heat affected zone (HAZ), C, thermomechanically affected zone (TMAZ), D, weld nugget (part of thermo-mechanically affected zone).

In the HAZ region the material only experiences the thermal cycle which will alter the microstructure and/or the mechanical properties. While in TMAZ region, the material is not only affected by the heat but also plastically deformed by the friction stir welding tool. For aluminum alloys, the recrystallized area in the TMAZ called the nugget zone which usually has a very fine grain structure.

The effect of pin radius, $R_{p i n}$, on the temperature distributions is illustrated in Figure 20. In this figure the shoulder angle, $\alpha_{\text {tool }}=0^{\circ}$ is fixed and contour plots of the temperature distributions are given for four different pin radius, $R_{\text {pin }}$, values of $1 \mathrm{~mm}, 1.5 \mathrm{~mm}, 2 \mathrm{~mm}$ and $2.5 \mathrm{~mm}$. Results of the temperature distributions for $\alpha_{\text {tool }}=2^{\circ}, 5^{\circ}, 8^{\circ}, 10^{\circ}$ are not included here for brevity.

As shown in previous section, in the plunge stage more frictional and plastic energy dissipations are generated by the tool with larger pins. This can be verified by checking the temperature value at a specific point of the workpiece using different tool pins. In Figure 20 all the tools have the same shoulder angle, $\alpha_{\text {tool }}=0^{\circ}$. The selected material point of the 
workpiece is shown on the first picture in Figure 20 by a red point. The temperatures at this point for $R_{\text {pin }}=1 \mathrm{~mm}, R_{\text {pin }}=1.5 \mathrm{~mm}, R_{\text {pin }}=2 \mathrm{~mm}$ and $R_{\text {pin }}=2.5 \mathrm{~mm}$ are about $80{ }^{\circ} \mathrm{C}, 120$ ${ }^{\circ} \mathrm{C}, 160{ }^{\circ} \mathrm{C}$ and $200{ }^{\circ} \mathrm{C}$, respectively. The relationship between temperature and pin radius is approximately linear. For the same plunging time, larger radius pins heat the material point to a higher temperature. It is also found that the maximum temperatures in each of these four pictures are very close to each other at around $520^{\circ} \mathrm{C}$. This means that there is a higher thermal gradient around the tool, close to the surface of the workpiece, for the case of smaller pin radius. A higher temperature gradient will lead to higher thermal stress and consequently higher deformation. The above findings are valid for all the shoulder surface angles considered here, not just $\alpha_{\text {tool }}=0^{\circ}$. A discussion on these detailed results is not included here for brevity.

As found previously, the shoulder surface angle, $\alpha_{\text {tool }}$, has little effect on the heat generation. Therefore, it is expected that it should not have much effect on temperature distribution in the workpiece. From inspection of results from finite element models which have the same pin radius, the discrepancy among them is very small. A slightly higher temperature at the sample point for bigger shoulder surface angle is due to the reason that the tool with bigger shoulder surface takes a slightly longer time to establish the full contact with the plates.

The shape of the hottest (red) part of workpiece in each picture also changes with different pins. Normally increasing the pin radius will enlarge the shape of this hottest part, in particular towards the bottom surface of the workpiece. Hence it is safe to say that the pin radius will also affect the size of the weld zone.

According to the classification of different weld zones, the size of the TMAZ and nugget will unquestionably be influenced by the pin size. The size of the HAZ will be broadened if larger pin is used since more heat will be generated. As the width of the tool shoulder is fixed in the present investigation, increasing the pin radius will only expand the TMAZ downwards inside the plates. This is consistent with the variation of the hottest zone shape found in the temperature distribution plots. A large part of nugget could be seen as a region displaced and passed by the tool pin, hence the pin volume is a good estimation of nugget size. 


\section{Conclusions}

The effects, in plunge stage, that the tool geometry in particular tool shoulder concavity angle and tool pin radius has on Friction Stir Welding process outcomes were studied. Specific process outcomes studied included tool reaction force, tool torque, heat generation, temperature distribution and size of the weld zone.

It was found that, before the shoulder contacted the plates, the larger the pin radius was, the higher force the tool experiences. Before the shoulder contacts the plates, only the pin is in contact with the workpiece. Hence the larger the pin radius, the larger the pin tip surface area, the larger the contact area, with the same plunge speed, so the higher force the tool experiences.

The effect of shoulder surface angle was detectable only when the shoulder was in contact with the workpiece, increasing shoulder surface angle decreased the peak reaction tool force for small radius pin tools $\left(R_{\text {pin }}=1 \mathrm{~mm}\right.$ and $R_{\text {pin }}=1.5 \mathrm{~mm}$ ). For larger radius pin tools ( $R_{\text {pin }}=2 \mathrm{~mm}$ and $R_{\text {pin }}=2.5 \mathrm{~mm}$ ), the shoulder surface angle had little effect on the peak tool forces. The tool with smaller shoulder angle always reaches the peak reaction force value earlier, indicating less time is required for plunge stage in this geometry configuration. This is related to the contact surface area when the shoulder is in contact with the workpiece. At the same plunge depth, the smaller the shoulder angle, the more contact area, with the same plunge speed, the earlier the tool reaches the full contact, so the earlier the tool experiences the peak force.

The effect of tool shape on tool reaction torque is very similar to that on tool reaction force due to an approximately proportional relationship between them.

In plunge stage the pin radius played an important role in both frictional dissipation and plastic dissipation. The greater the pin radius, the more heat generated due to increased contact area. The heat energy increased nearly bi-linearly with time, with a small increment rate before the shoulder contacted the workpiece and a much greater increment rate thereafter. The shoulder angle had very little effect on energy dissipation as well as little effect on temperature distribution. This effect was particularly evident in models with larger pin radi. This is because the ratio of shoulder surface to pin surface is smaller. The 
shoulder has a smaller portion of the total contact surface area, so the effect of the variation of heat generated by shoulder surface on the total frictional heat is smaller.

It is also found that increasing pin radius will increase the size of HAZ, TMAZ and nugget zone.

\section{References}

[1] A. Barcellona, G. Buffa, L. Fratini, "Pin shape effect on friction stir welding of AA 6082-T6 sheets", Proceedings of the 4th CIRP international seminar on intelligent computation in manufacturing engineering (ICME 04), Sorrento, Italy, 30 June-2 July, 2004, pp. 499-502.

[2] O.T. Midling, G. Rørvik, "Effect of tool shoulder material on heat input during friction stir welding", Proceedings of the 1st international friction stir welding symposium, Oaks (CA, USA), 14-16 June, 1999.

[3] CJ. Dawes, WM. Thomas, "Development of improved tool designs for friction stir welding of aluminium", Proceedings of the 1st international friction stir welding symposium, Oaks (CA, USA), 14-16 June, 1999.

[4] D.G. Hattingh, C. Blignault, T.I. van Niekerk, M.N. James, "Characterization of the influences of FSW tool geometry on welding forces and weld tensile strength using an instrumented tool", Journal of Materials Processing Technology, Volume 203, Issues 1-3, 18 July 2008, pp. 46-57.

[5] K. Elangovan, V. Balasubramanian, "Influences of tool pin profile and tool shoulder diameter on the formation of friction stir processing zone in AA6061 aluminium alloy", Materials \& Design, Volume 29, Issue 2, 2008, pp. 362-373.

[6] K. Elangovan, V. Balasubramanian, "Influences of tool pin profile and welding speed on the formation of friction stir processing zone in AA2219 aluminium alloy", Journal of Materials Processing Technology, Volume 200, Issues 1-3, 8 May 2008, pp. 163-175.

[7] Hidetoshi Fujii, Ling Cui, Masakatsu Maeda, Kiyoshi Nogi, "Effect of tool shape on mechanical properties and microstructure of friction stir welded aluminum alloys", Materials Science and Engineering: A, Volume 419, Issues 1-2, 15 March 2006, pp. 25-31.

[8] A. Scialpi, L.A.C. De Filippis, P. Cavaliere, "Influence of shoulder geometry on microstructure and mechanical properties of friction stir welded 6082 aluminium alloy”, Materials \& Design, Volume 28, Issue 4, 2007, pp. 1124-1129. 
[9] Mustafa Boz, Adem Kurt, "The influence of stirrer geometry on bonding and mechanical properties in friction stir welding process", Materials \& Design, Volume 25, Issue 4, June 2004, pp. 343-347

[10] P.A. Colegrove, H.R. Shercliff, "Development of Trivex friction stir welding tool Part 1 - two-dimensional flow modelling and experimental validation", Science and Technology of Welding \& Joining, Volume 9, Number 4, August 2004 , pp. 345-351.

[11] G. Buffa, J. Hua, R. Shivpuri, L. Fratini, "A Continuum Based Fem Model for Friction Stir Welding-Model Development", Material Science and Engineering A, Vol. 419, Issues 1-2, 2006, pp. 389-396.

[12] T.U. Seidel and A.P. Reynolds, "Visualization of the Material Flow in AA2195 Friction-Stir Welds Using a Marker Insert Technique", Metallurgical and materials Transactions A, 32, 2001, pp. 2879.

[13] C.M. Chen, R. Kovacevic, "Finite Element Modelling of Friction Stir WeldingThermal and Thermomechanical analysis", International Journal of Machine Tols and Manufacture, Vol. 43, 2003, pp. 1319-1326.

[14] Moataz M. Attallaha and Hanadi G. Salem, "Friction stir welding parameters: a tool for controlling abnormal grain growth during subsequent heat treatment", Materials Science and Engineering A, Vol. 391, Issues 1-2, 2005, pp. 51-59.

[15] H.N.B. Schmidt, T.L. Dickerson, and J.H. Hattel, "Material flow in butt friction stir welds in AA2024-T3", Acta Materialia, Vol. 54, 2006, pp.1199-1209.

[16] H.W. Zhang, Z. Zhang, J.T. Chen, "3D modeling of material flow in friction stir welding under different process parameters", Journal of Materials Processing Technology, Volume 183, 2007, 62-70.

[17] G. Buffa, L. Fratini, R. Shivpuri, "Finite element studies on friction stir welding processes of tailored blanks", Computers \& Structures, Volume 86, 2008, 181-189.

[18] Y.M. Hwang, Z.W. Kang, Y.C. Chiou, H.H. Hsu, "Experimental study on temperature distributions within the workpiece during friction stir welding of aluminum alloys", International Journal of Machine Tools \& Manufacture, Volume 48, 2008, 778-787.

[19] C. Blignault, D.G. Hattingh, G.H. Kruger, T.I. van Niekerk, M.N. James, "Friction stir weld process evaluation by multi-axial transducer", Measurement, Volume 41, 2008, 32-43.

[20] Hongjun Li and Donald Mackenzie, "Coupled Thermo-Mechanical Modeling of Friction Stir Welding", Proceedings of the 2007 ASME Pressure Vessels and Piping Conference and 8th International Conference on CREEP and Fatigue at Elevated Temperature, July 22 - 26, 2007.

[21] ABAQUS/EXPLICIT (2006), Version 6.6-1, ABAQUS, Inc., Providence, USA. 
Table 1 Typical tool geometries used in the literature.

\begin{tabular}{|l|l|l|l|l|l|l|}
\hline Reference & Material & Pin Height & $\begin{array}{l}\mathbf{R}_{\text {pin }} \\
(\mathbf{m m})\end{array}$ & $\begin{array}{l}\mathbf{R}_{\text {shoulder }} \\
(\mathbf{m m})\end{array}$ & $\mathbf{R}_{\text {shoulder }} / \mathbf{R}_{\text {pin }}$ & $\boldsymbol{\alpha}_{\text {tool }}$ \\
\hline $\begin{array}{l}\text { Colegrove } \\
{[10]}\end{array}$ & AA5083 & 6.2 & 4.0 & 12.5 & 3.1 & $7.0^{\circ}$ \\
\hline $\begin{array}{l}\text { Buffa } \\
{[16]}\end{array}$ & AA6061 & 2.8 & 1.5 & 5.0 & 3.3 & $0.0^{\circ}$ \\
\hline $\begin{array}{l}\text { Seidel } \\
{[17]}\end{array}$ & AA7075 & 7.9 & 5.0 & 12.7 & 2.6 & $7.0^{\circ}$ \\
\hline $\begin{array}{l}\text { Chen } \\
{[18]}\end{array}$ & AA6061 & -- & 3.0 & 12.0 & 4.0 & $10.0^{\circ}$ \\
\hline $\begin{array}{l}\text { Moataz } \\
{[19]}\end{array}$ & AA2095 & 1.5 & 1.9 & 5.0 & 2.6 & - \\
\hline Schmidt & AA2024 & -- & 3.0 & 3.0 & - \\
\hline
\end{tabular}




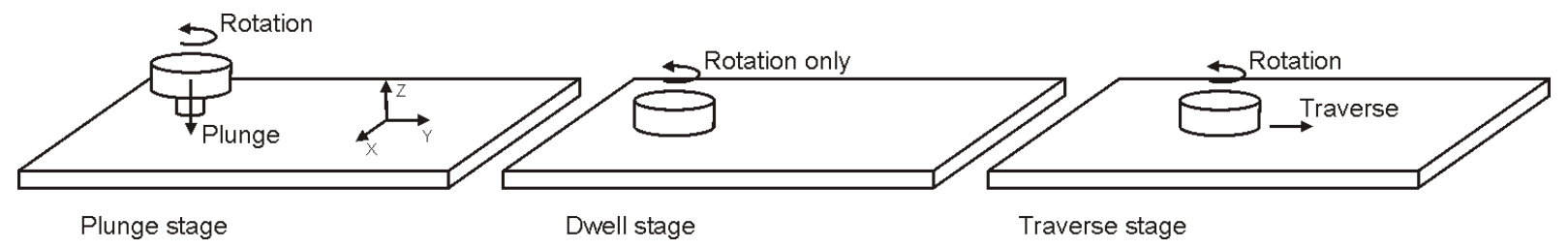

Figure 1. Illustration of the friction stir welding process. 


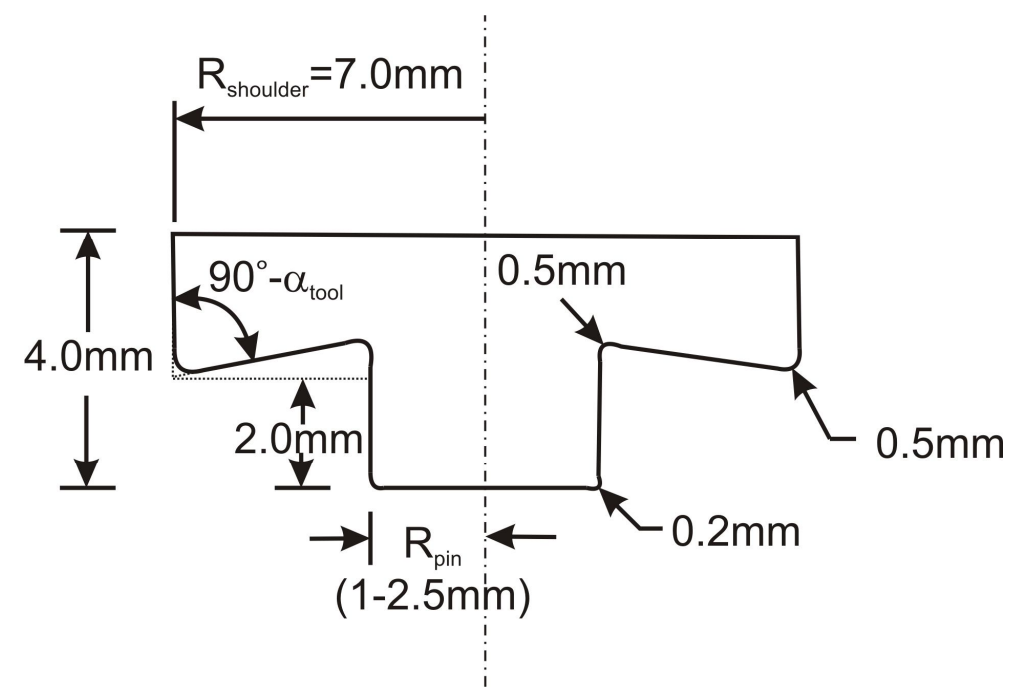

Figure 2. Tool design used for tool shape study. 


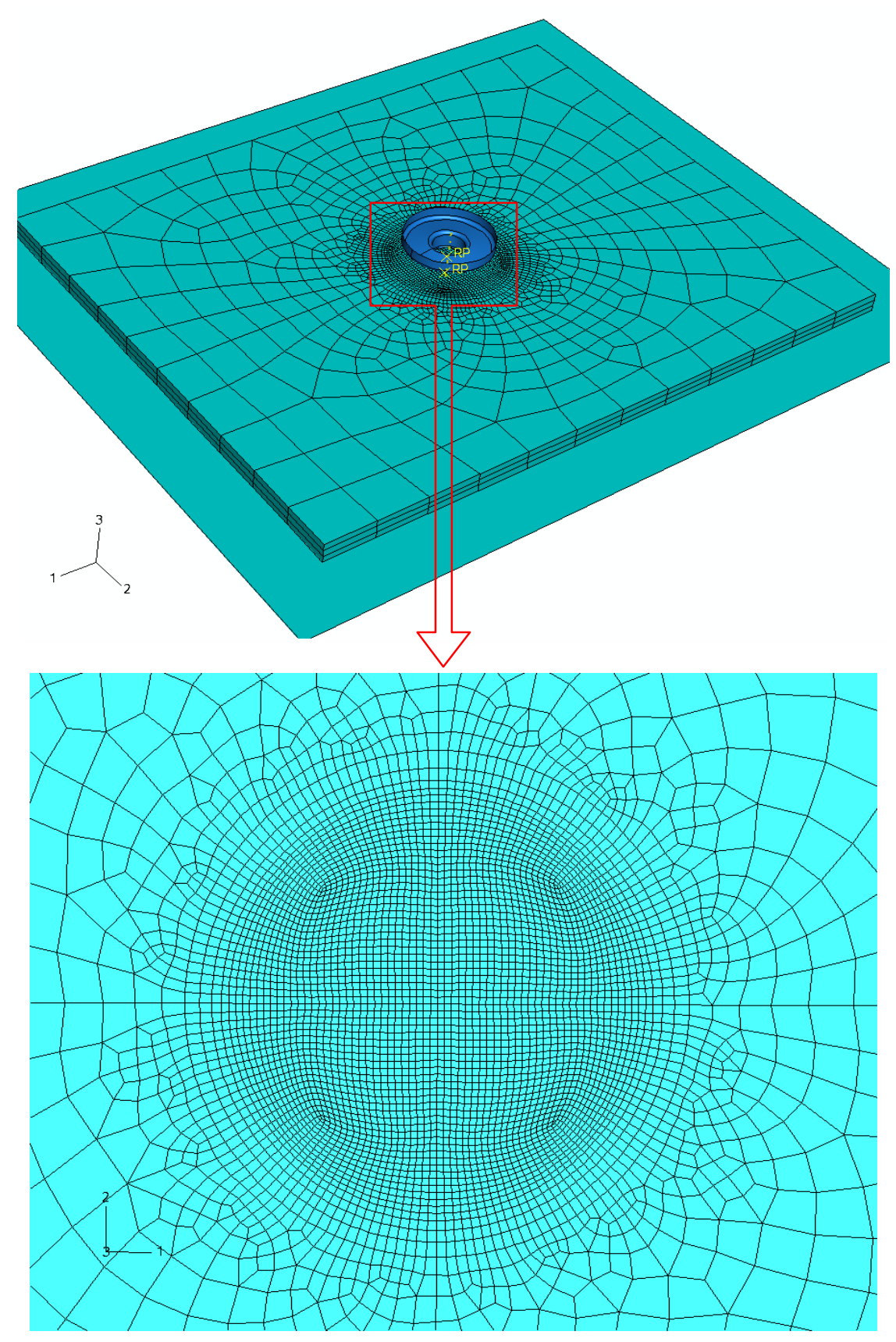

Figure 3 The FE mesh for studying the effect of tool shape. 


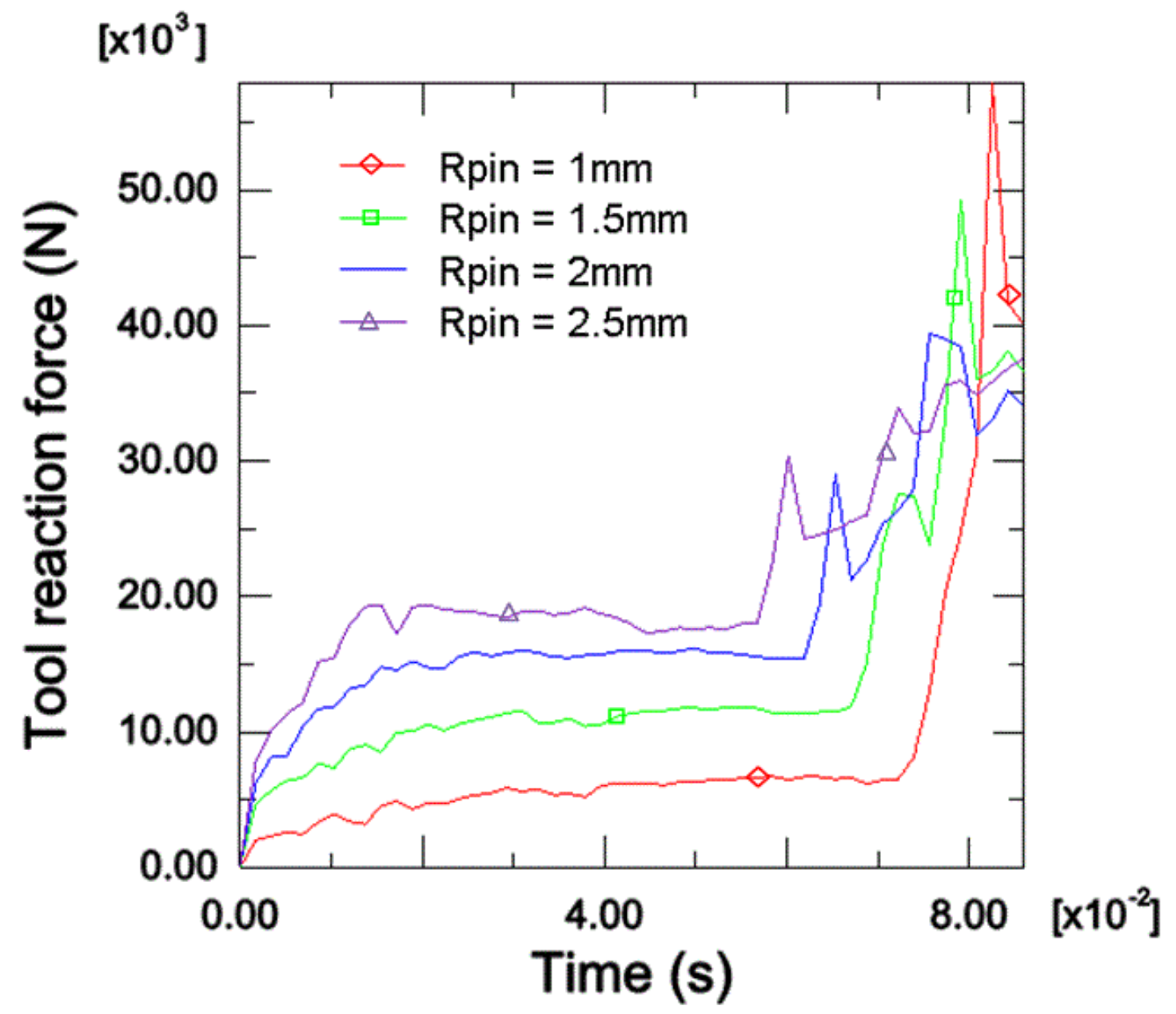

Figure 4 Plots of tool reaction force against time in plunge stage, $\alpha_{\text {tool }}=0^{\circ}$, for $R_{\text {pin }}=1,1.5$, 2 and $2.5 \mathrm{~mm}$. 


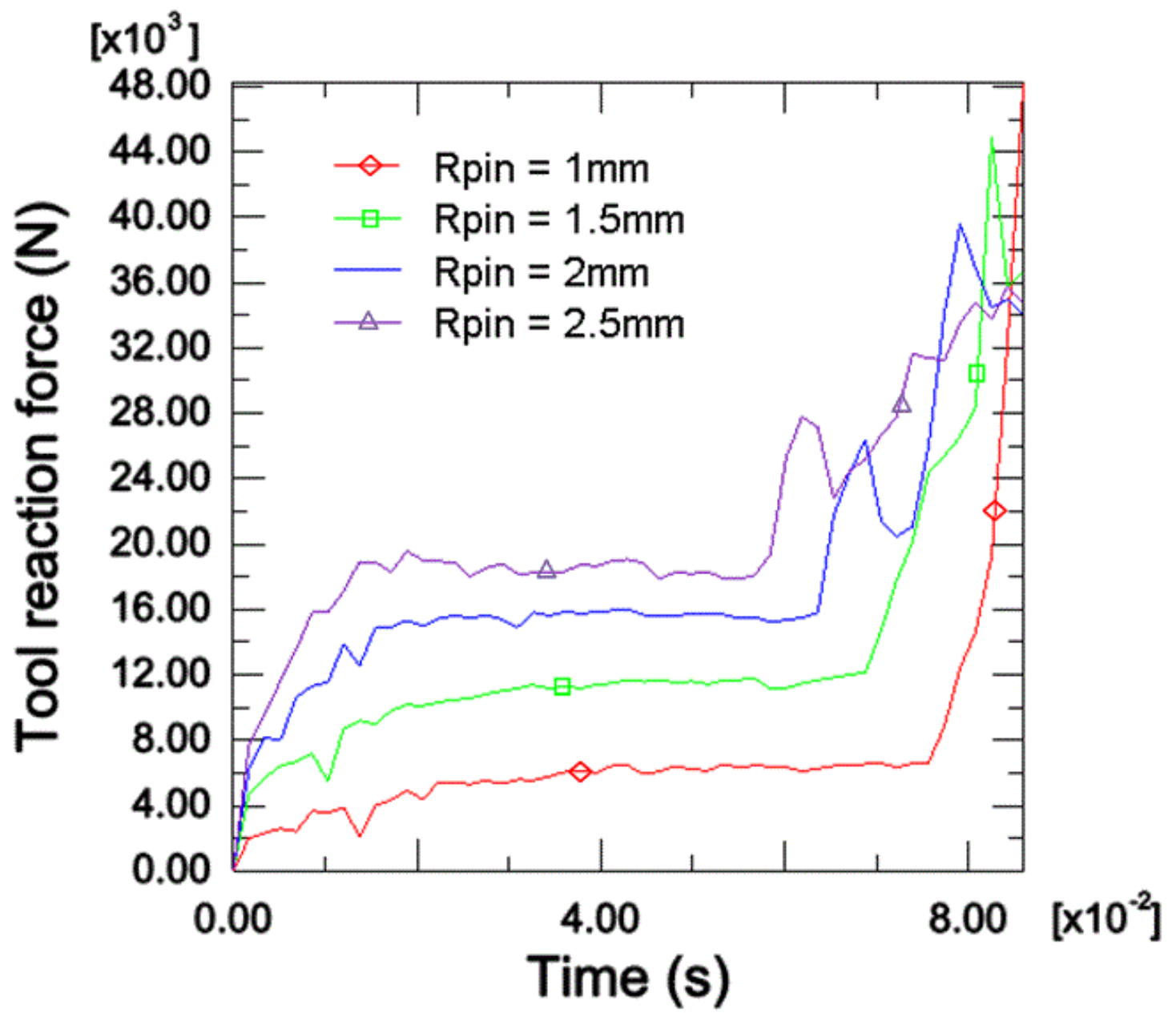

Figure 5 Plots of tool reaction force against time in plunge stage, $\alpha_{\text {tool }}=2^{\circ}$, for $R_{\text {pin }}=1,1.5$, 2 and $2.5 \mathrm{~mm}$. 


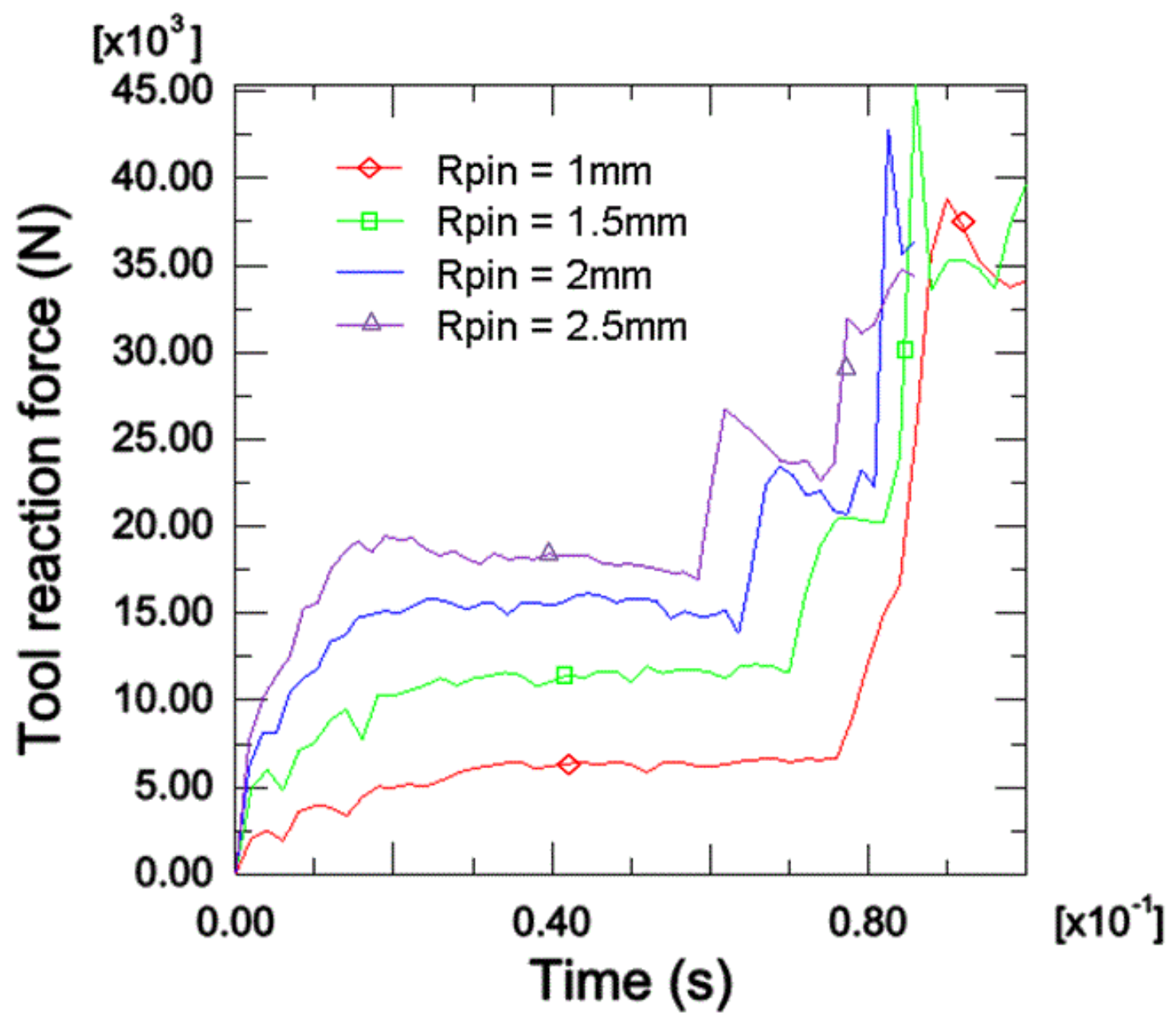

Figure 6 Plots of tool reaction force against time in plunge stage, $\alpha_{\text {tool }}=5^{\circ}$, for $R_{\text {pin }}=1,1.5$, 2 and $2.5 \mathrm{~mm}$. 


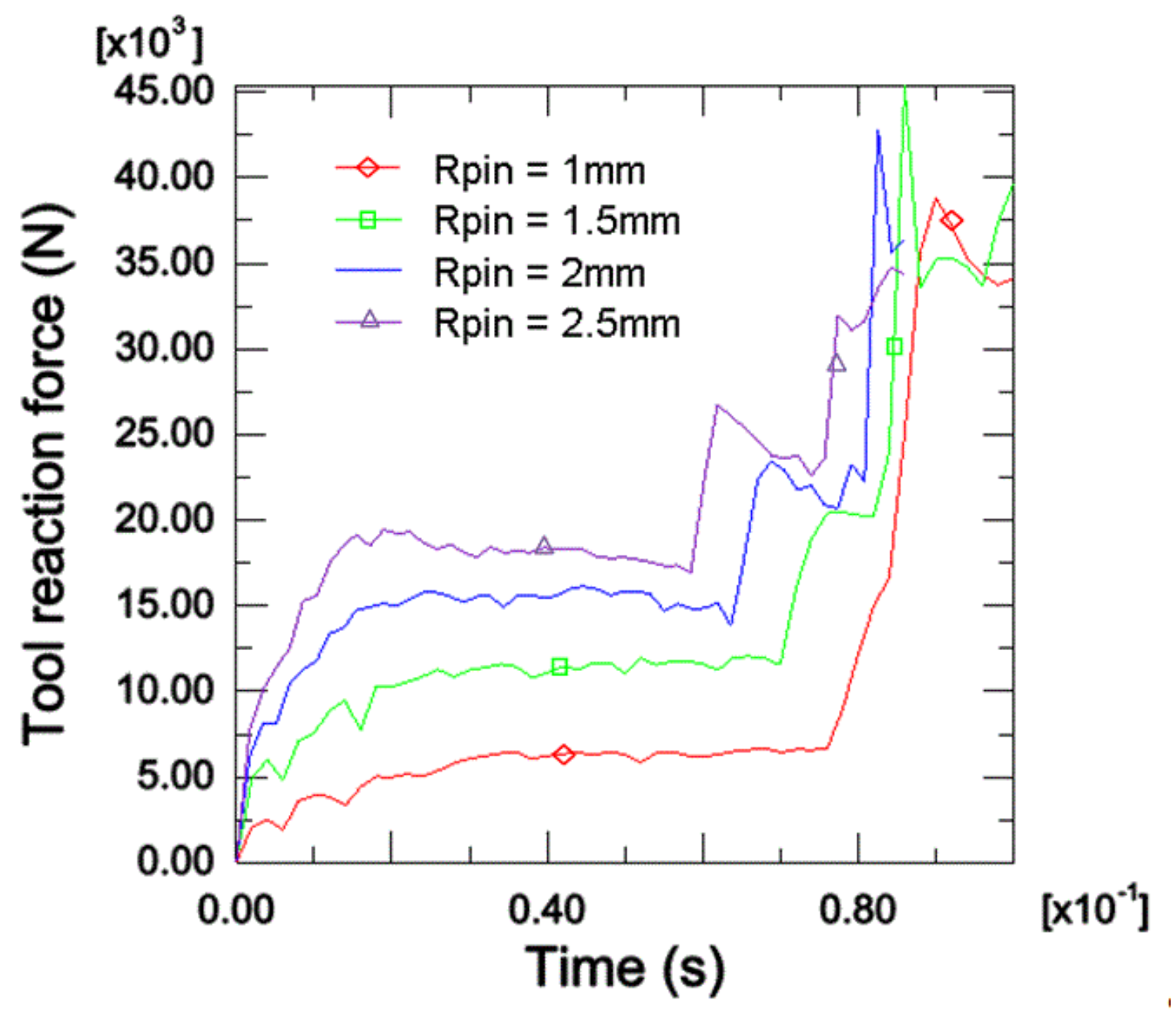

Figure 7 Plots of tool reaction force against time in plunge stage, $\alpha_{\text {tool }}=8^{\circ}$, for $R_{\text {pin }}=1,1.5$, 2 and $2.5 \mathrm{~mm}$. 


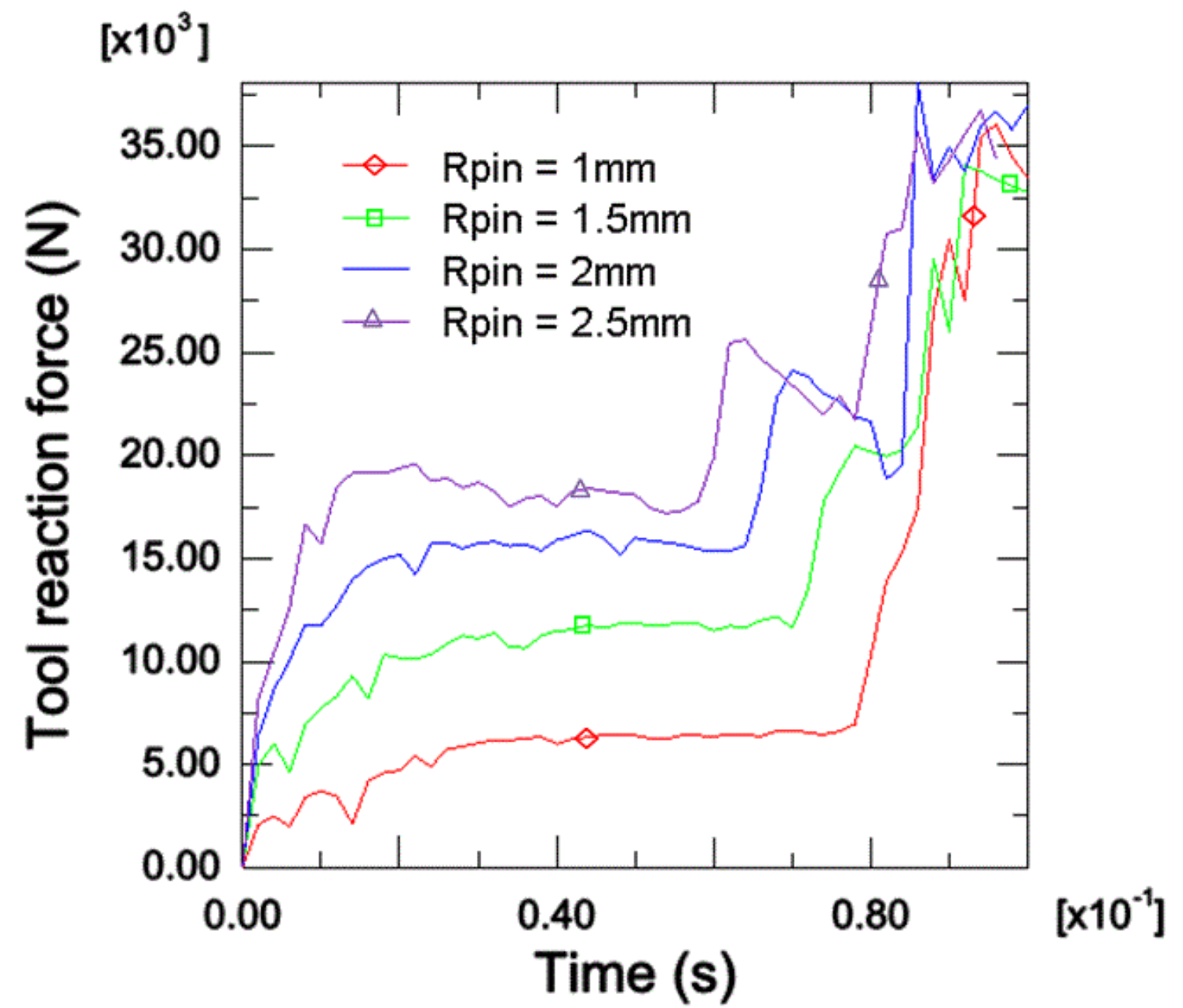

Figure 8 Plots of tool reaction force against time in plunge stage, $\alpha_{\text {tool }}=10^{\circ}$, for $R_{\text {pin }}=1$, $1.5,2$ and $2.5 \mathrm{~mm}$. 


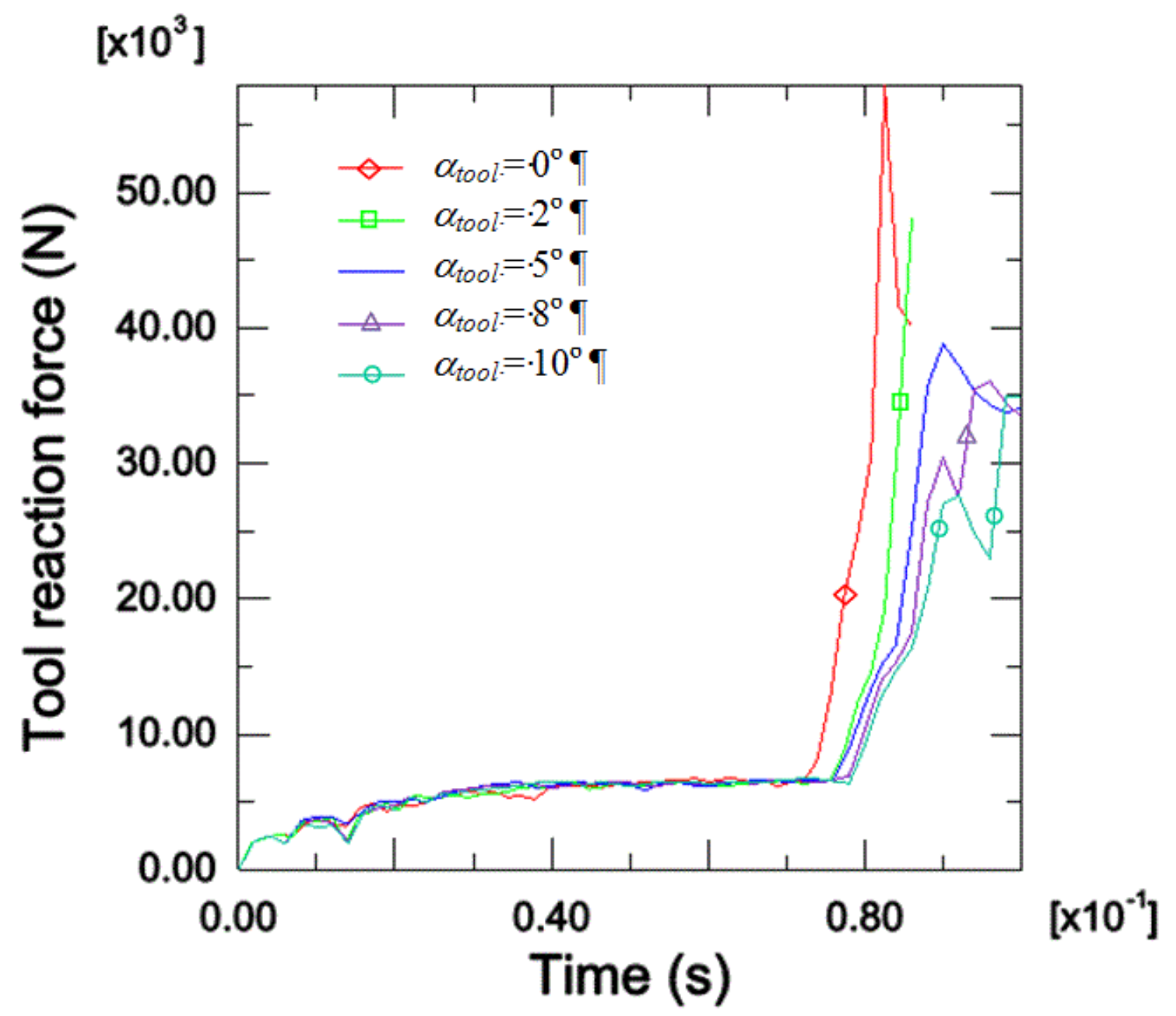

Figure 9 Plots of tool reaction force against time in plunge stage, $R_{p i n}=1$, for $\alpha_{\text {tool }}=0^{\circ}$, $\alpha_{\text {tool }}=2^{\circ} \alpha_{\text {tool }}=5^{\circ} \alpha_{\text {tool }}=8^{\circ}$ and $\alpha_{\text {tool }}=10^{\circ}$. 


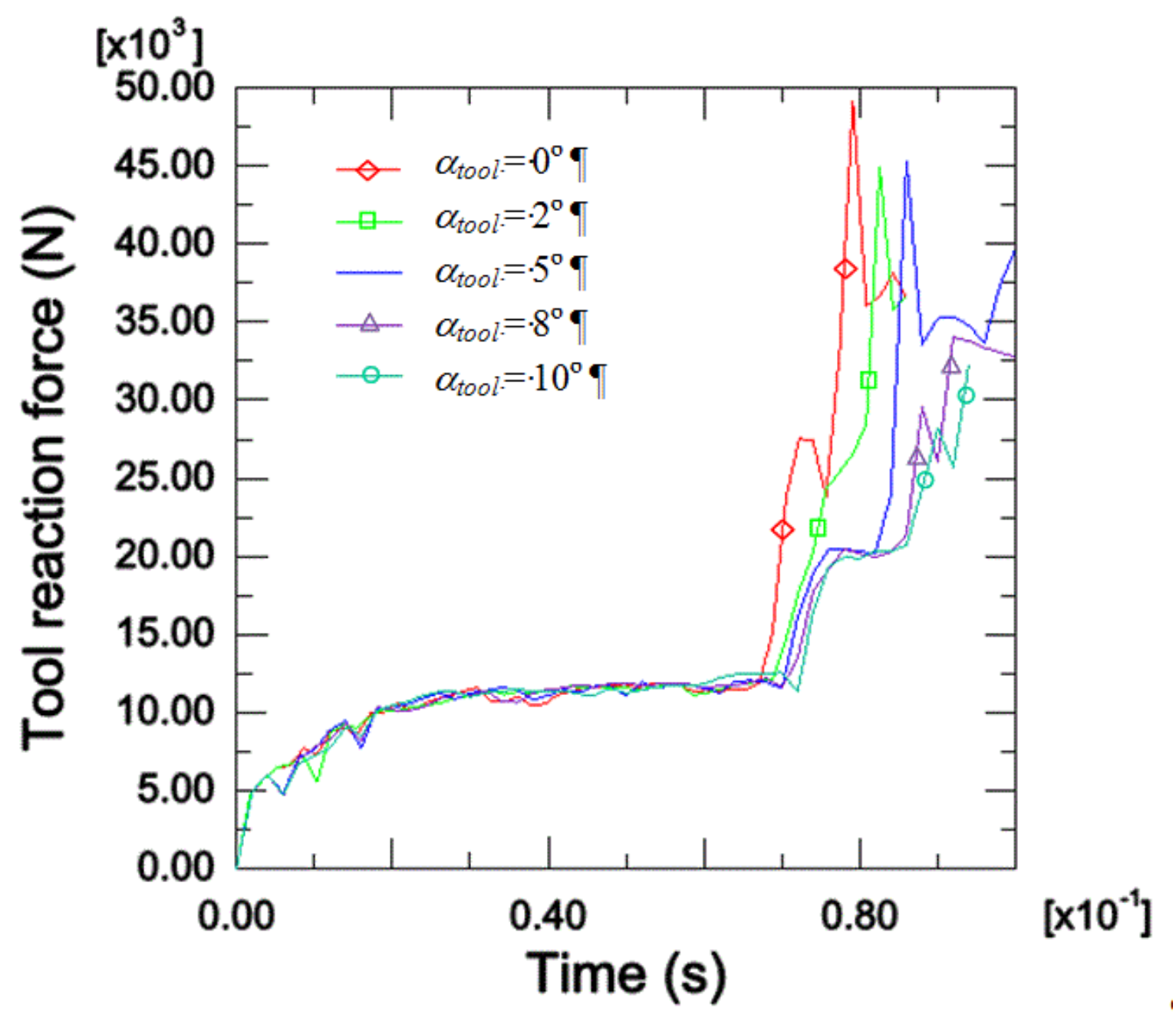

Figure 10 Plots of tool reaction force against time in plunge stage, $R_{p i n}=1.5$, for $\alpha_{\text {tool }}=0^{\circ}$, $\alpha_{\text {tool }}=2^{\circ} \alpha_{\text {tool }}=5^{\circ} \alpha_{\text {tool }}=8^{\circ}$ and $\alpha_{\text {tool }}=10^{\circ}$. 


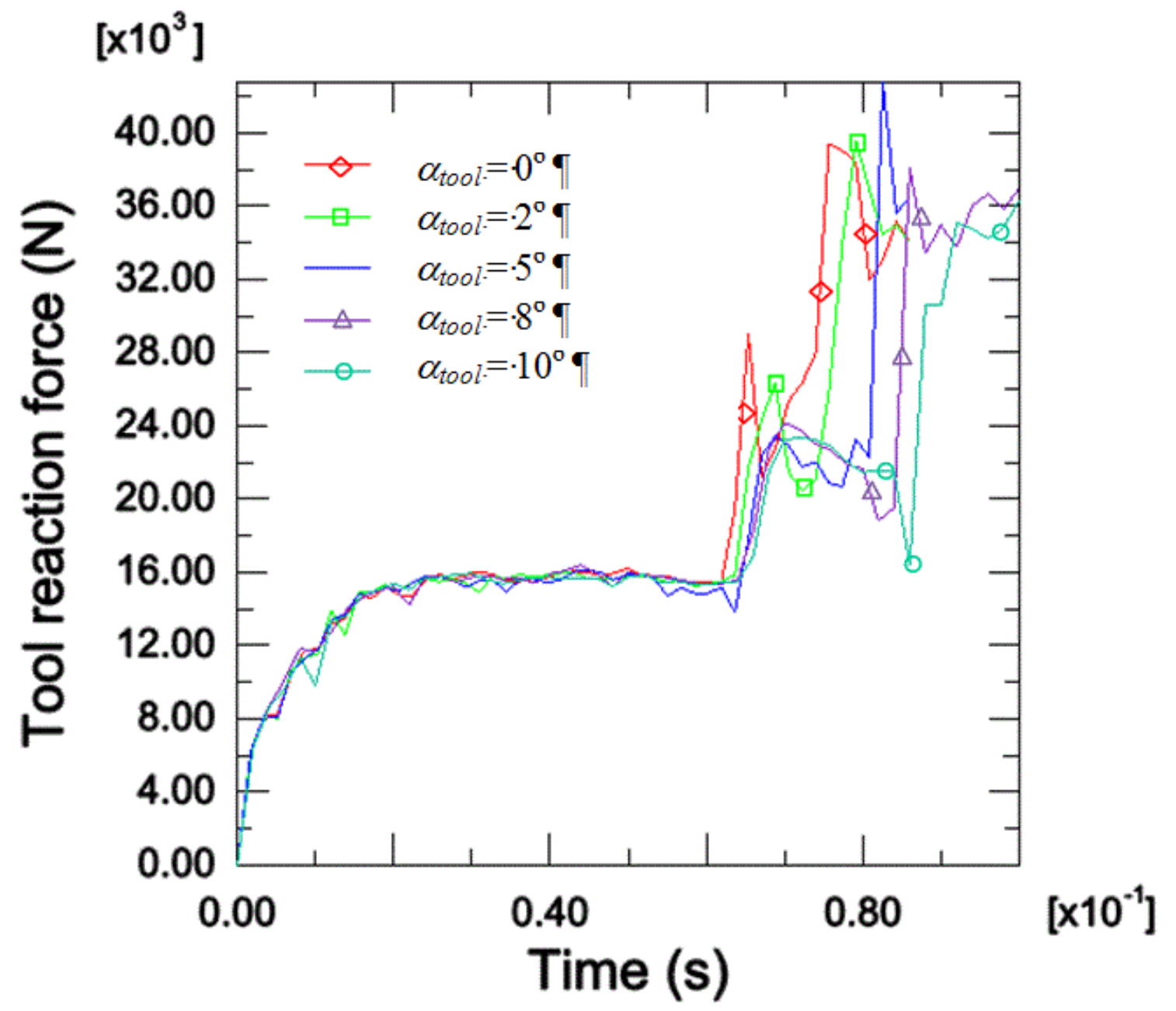

Figure 11 Plots of tool reaction force against time in plunge stage, $R_{p i n}=2$, for $\alpha_{\text {tool }}=0^{\circ}$, $\alpha_{\text {tool }}=2^{\circ} \alpha_{\text {tool }}=5^{\circ} \alpha_{\text {tool }}=8^{\circ}$ and $\alpha_{\text {tool }}=10^{\circ}$. 


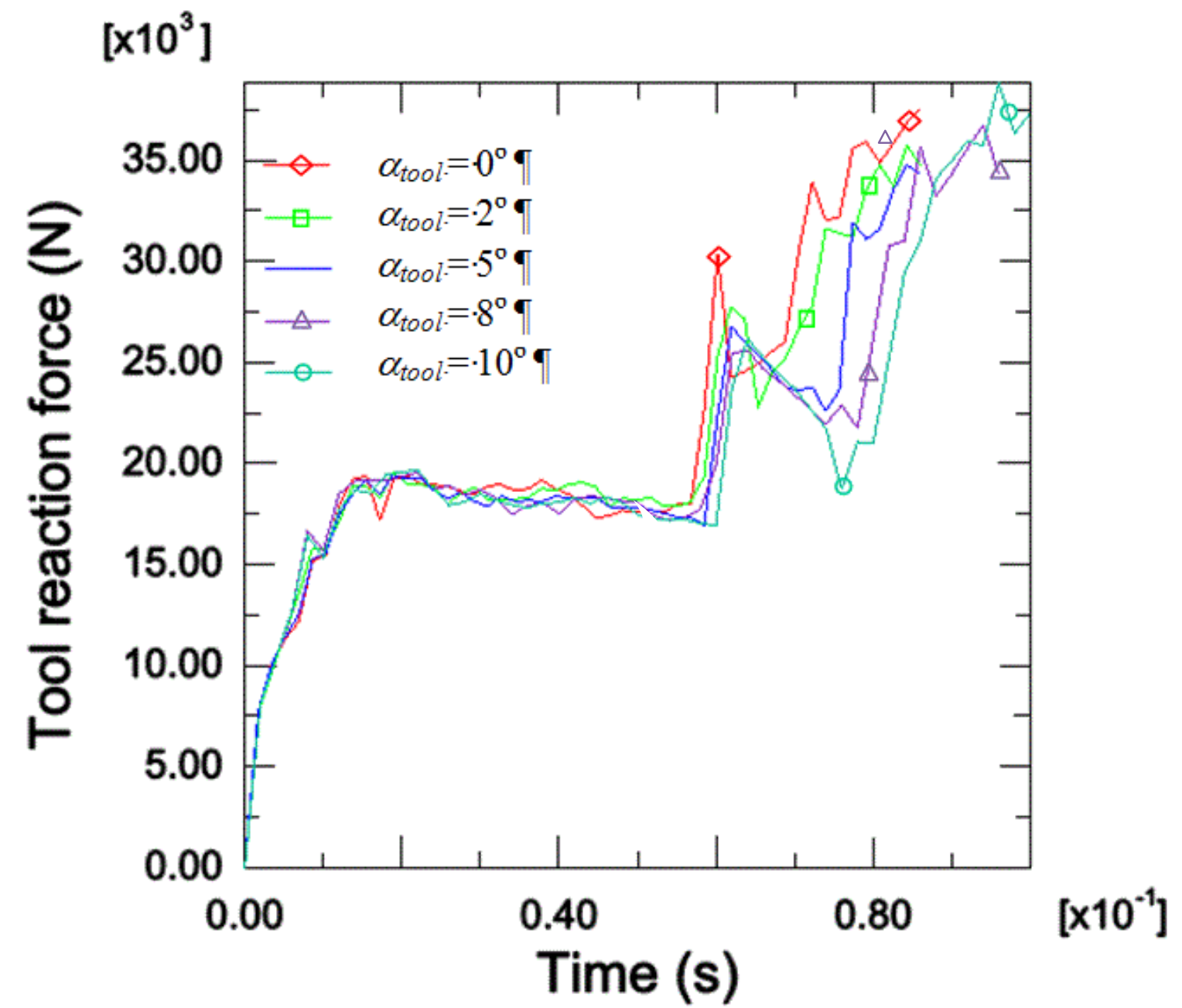

Figure 12 Plots of tool reaction force against time in plunge stage, $R_{p i n}=2.5$, for $\alpha_{\text {tool }}=0^{\circ}$, $\alpha_{\text {tool }}=2^{\mathrm{o}} \alpha_{\text {tool }}=5^{\mathrm{o}} \alpha_{\text {tool }}=8^{\mathrm{o}}$ and $\alpha_{\text {tool }}=10^{\mathrm{o}}$. 

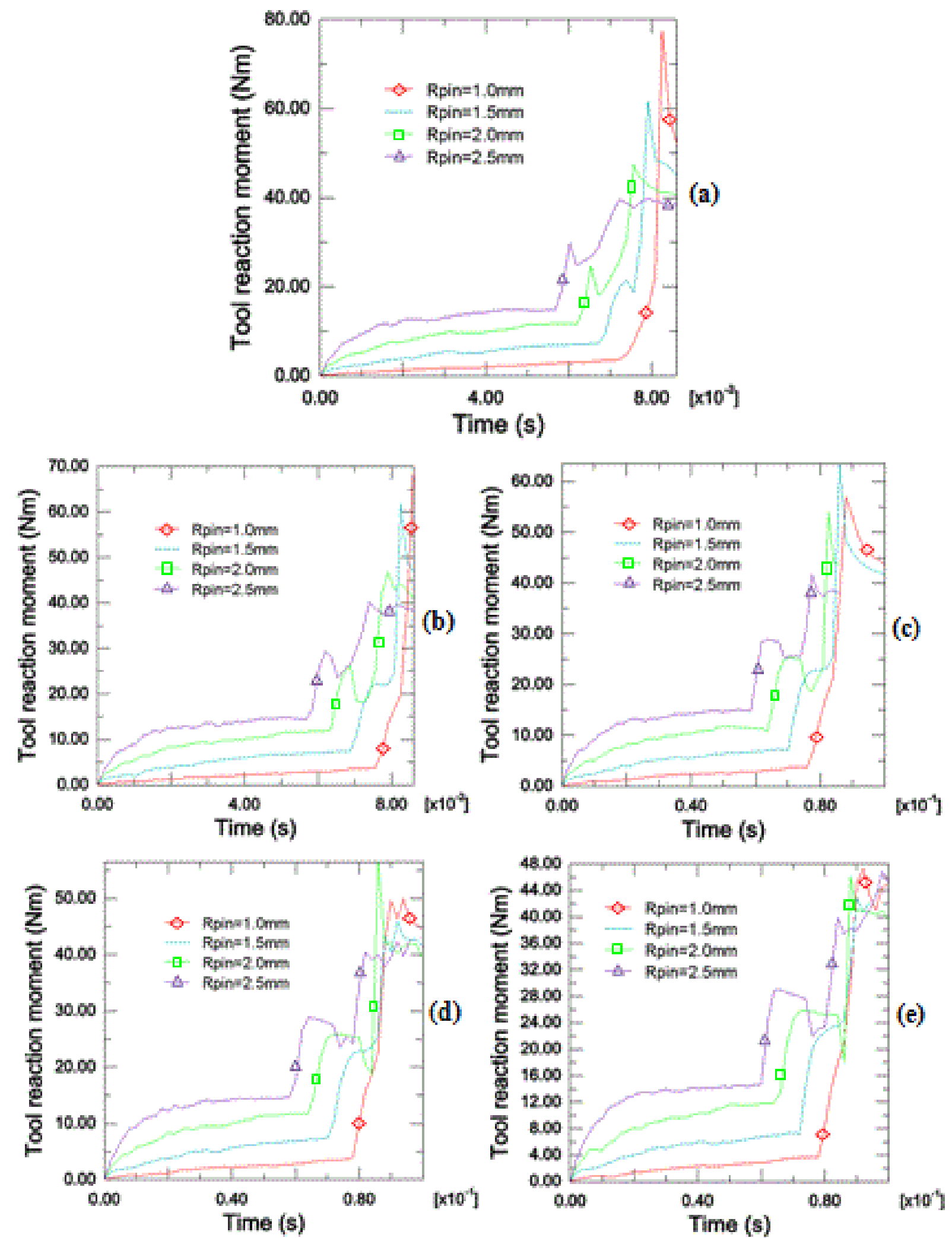

Figure 13 Plots of tool reaction moment against time in plunge stage, (a) $\alpha_{\text {tool }}=0^{\circ}$, (b) $\alpha_{\text {tool }}=2^{\circ}$, (c) $\alpha_{\text {tool }}=5^{\circ}$, (d) $\alpha_{\text {tool }}=8^{\circ}$, (e) $\alpha_{\text {tool }}=10^{\circ}$ for $R_{\text {pin }}=1,1.5,2$ and $2.5 \mathrm{~mm}$. 

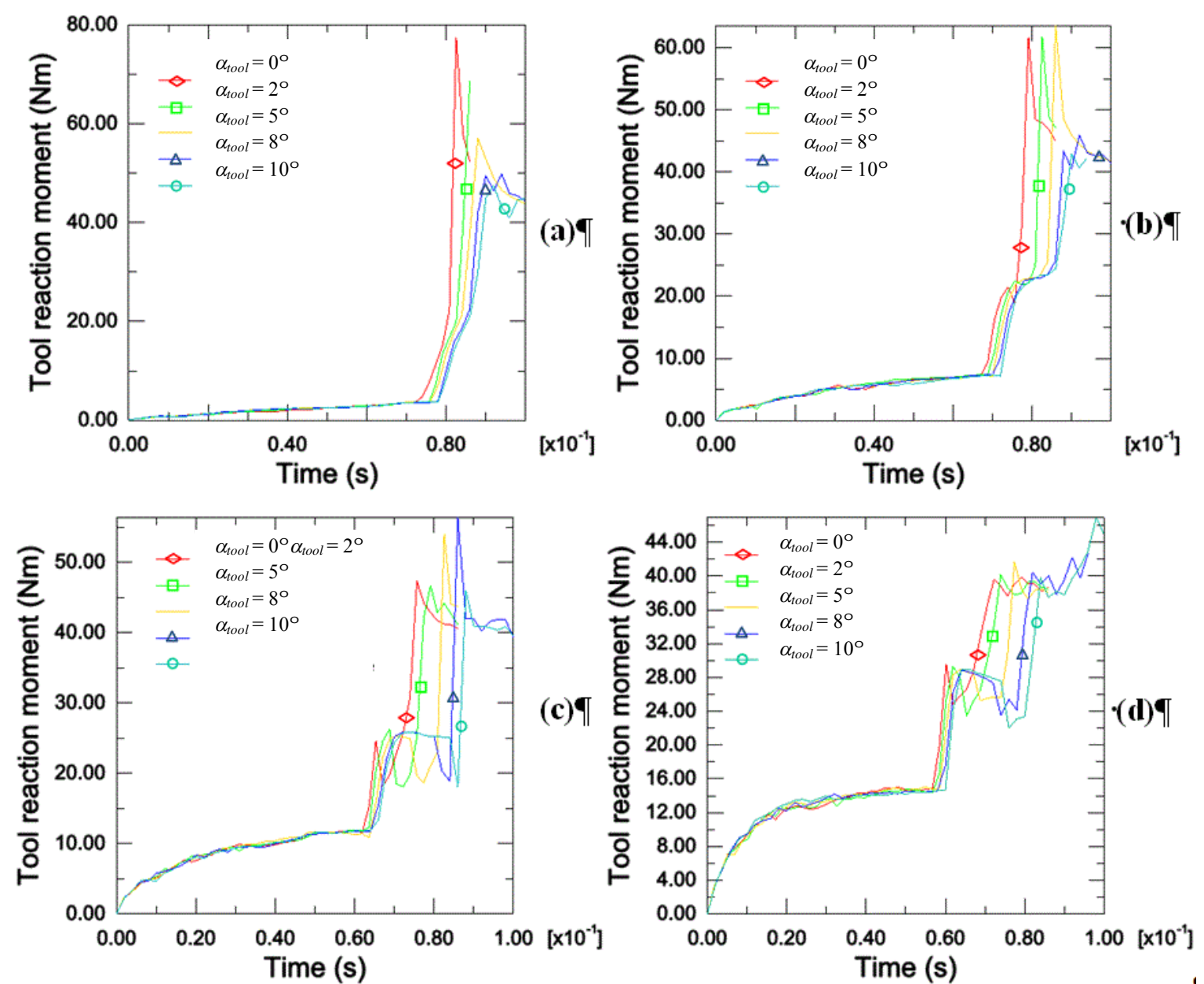

Figure 14 Plots of tool reaction moment against time in plunge stage, (a) $R_{\text {pin }}=1 \mathrm{~mm}$, (b) $R_{\text {pin }}=1.5 \mathrm{~mm}$, (c) $R_{\text {pin }}=2 \mathrm{~mm},(\mathrm{~d}) R_{\text {pin }}=2.5 \mathrm{~mm}$ : for $\alpha_{\text {tool }}=0^{\circ}, \alpha_{\text {tool }}=2^{\circ} \alpha_{\text {tool }}=5^{\circ} \alpha_{\text {tool }}$ $=8^{\circ}$ and $\alpha_{\text {tool }}=10^{\circ}$. 

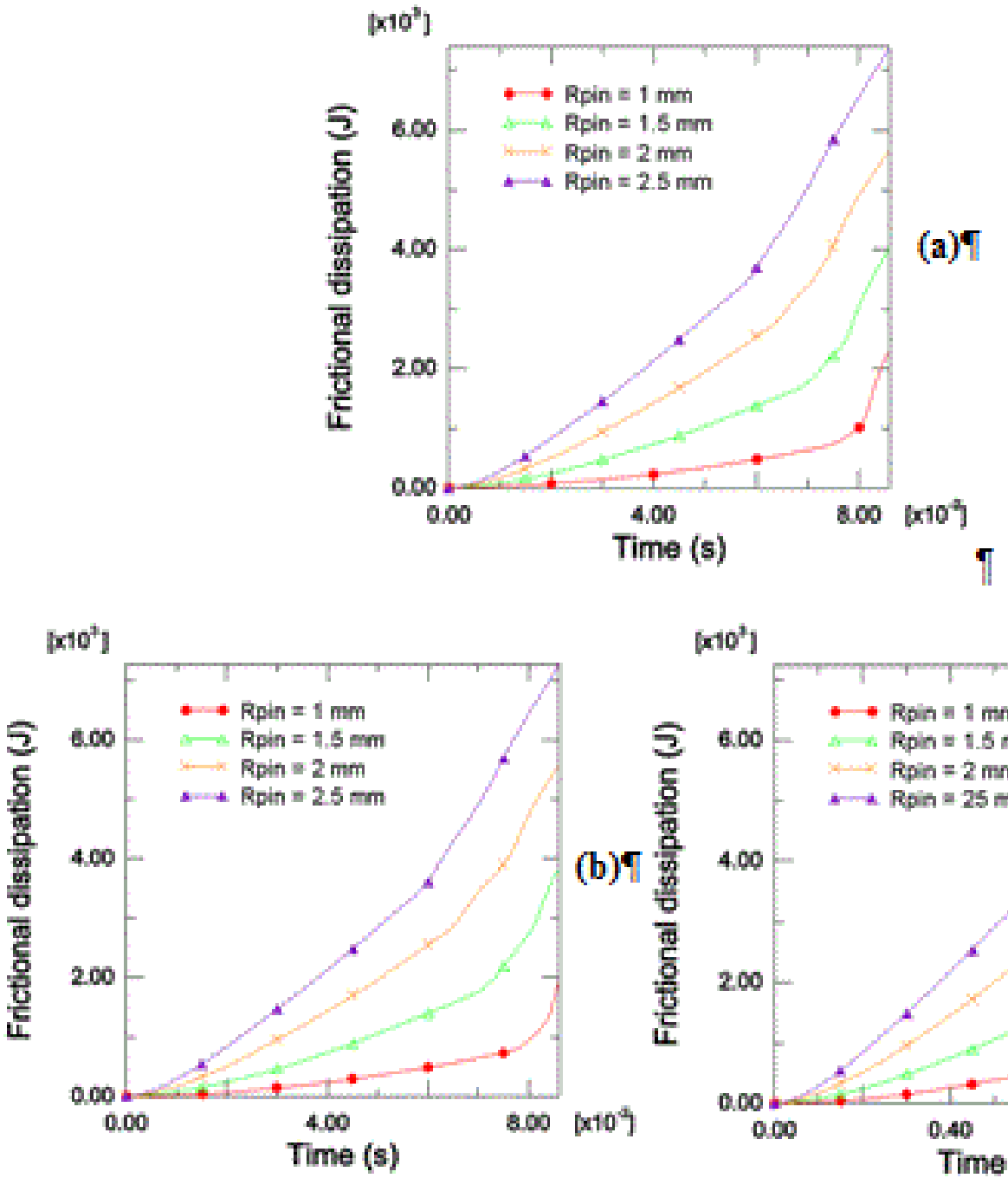

[x10 ]
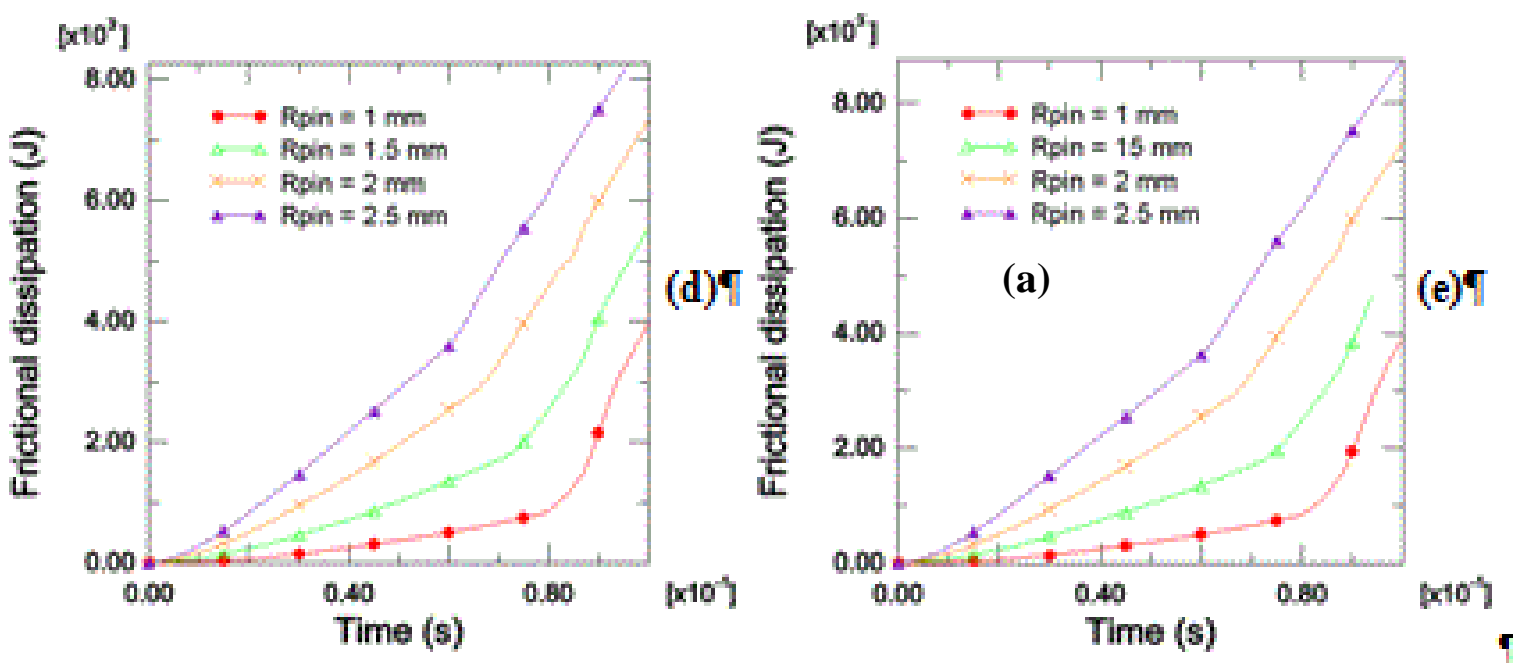

Figure 15 plots of frictional dissipation against time in plunge stage, (a) $\alpha_{\text {tool }}=0^{\circ}$, (b) $\alpha_{\text {tool }}$ $=2^{\circ}$, (c) $\alpha_{\text {tool }}=5^{\circ}$, (d) $\alpha_{\text {tool }}=8^{\circ}$, (e) $\alpha_{\text {tool }}=10^{\circ}$ : for $R_{\text {pin }}=1,1.5,2$ and $2.5 \mathrm{~mm}$. 

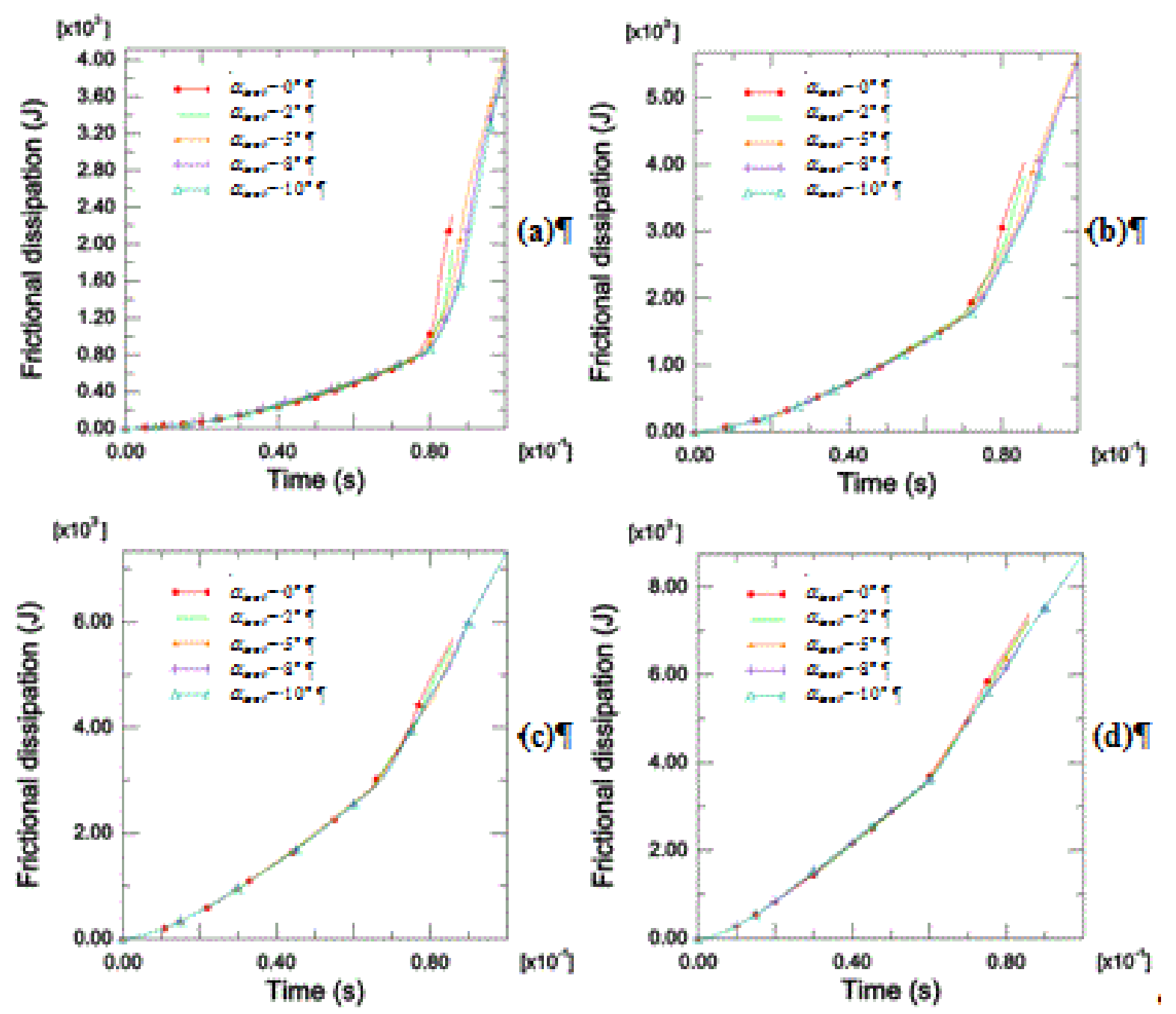

Figure 16 Plots of frictional dissipation against time in plunge stage (a) $R_{\text {pin }}=1 \mathrm{~mm}$, (b) $R_{\text {pin }}=1.5 \mathrm{~mm}$, (c) $R_{\text {pin }}=2 \mathrm{~mm}$, (d) $R_{\text {pin }}=2.5 \mathrm{~mm}$ : for $\alpha_{\text {tool }}=0^{\circ}, 2^{\circ}, 5^{\circ}, 8^{\circ}$ and $10^{\circ}$. 

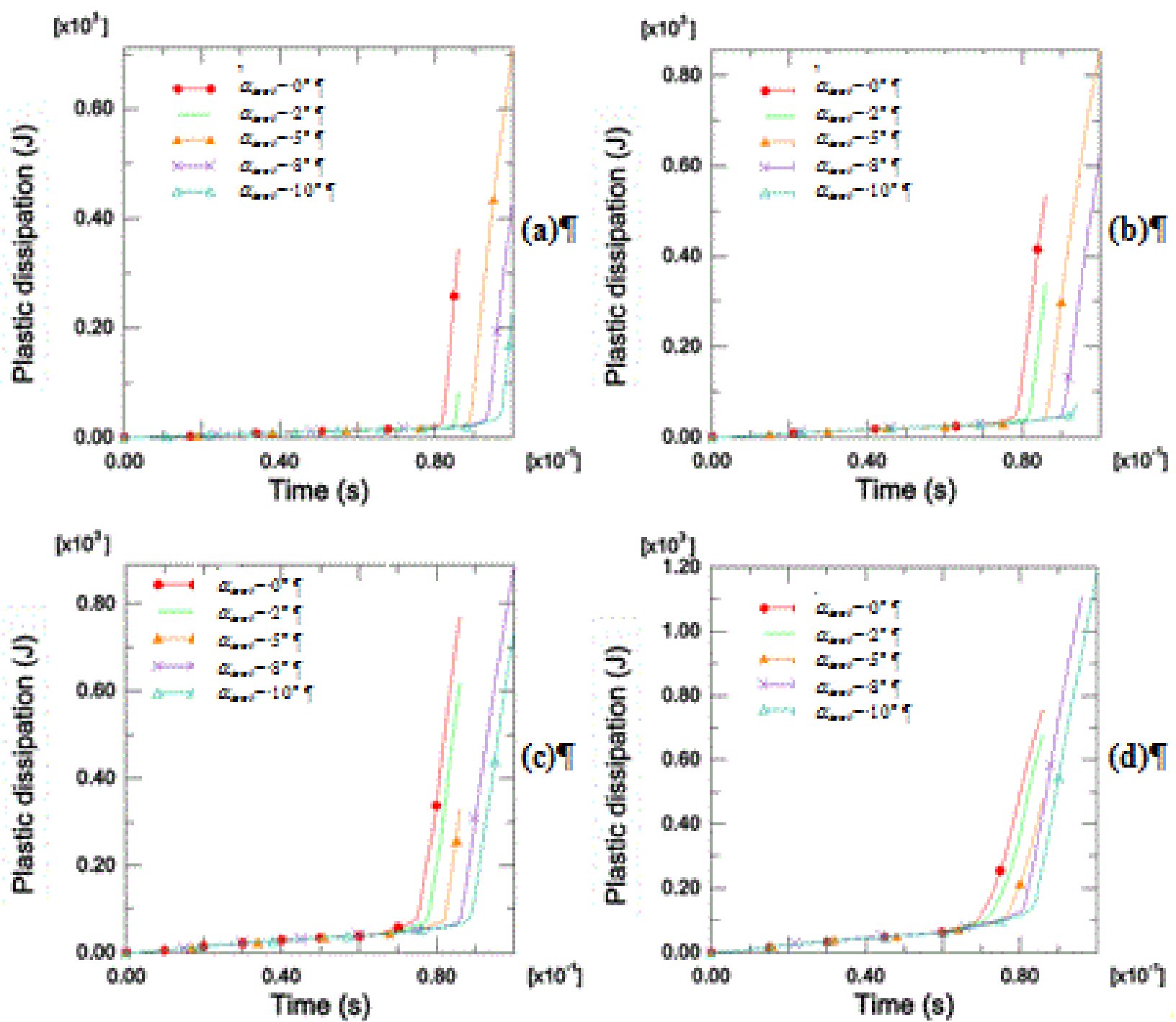

Figure 17 Plots of plastic dissipation against time in plunge stage for (a) $R_{\text {pin }}=1 \mathrm{~mm}$, (b) $R_{\text {pin }}=1.5 \mathrm{~mm}$, (c) $R_{\text {pin }}=2 \mathrm{~mm}$, (d) $R_{\text {pin }}=2.5 \mathrm{~mm}$ : for $\alpha_{\text {tool }}=0^{\circ}, 2^{\circ}, 5^{\circ}, 8^{\circ}$ and $10^{\circ}$. 

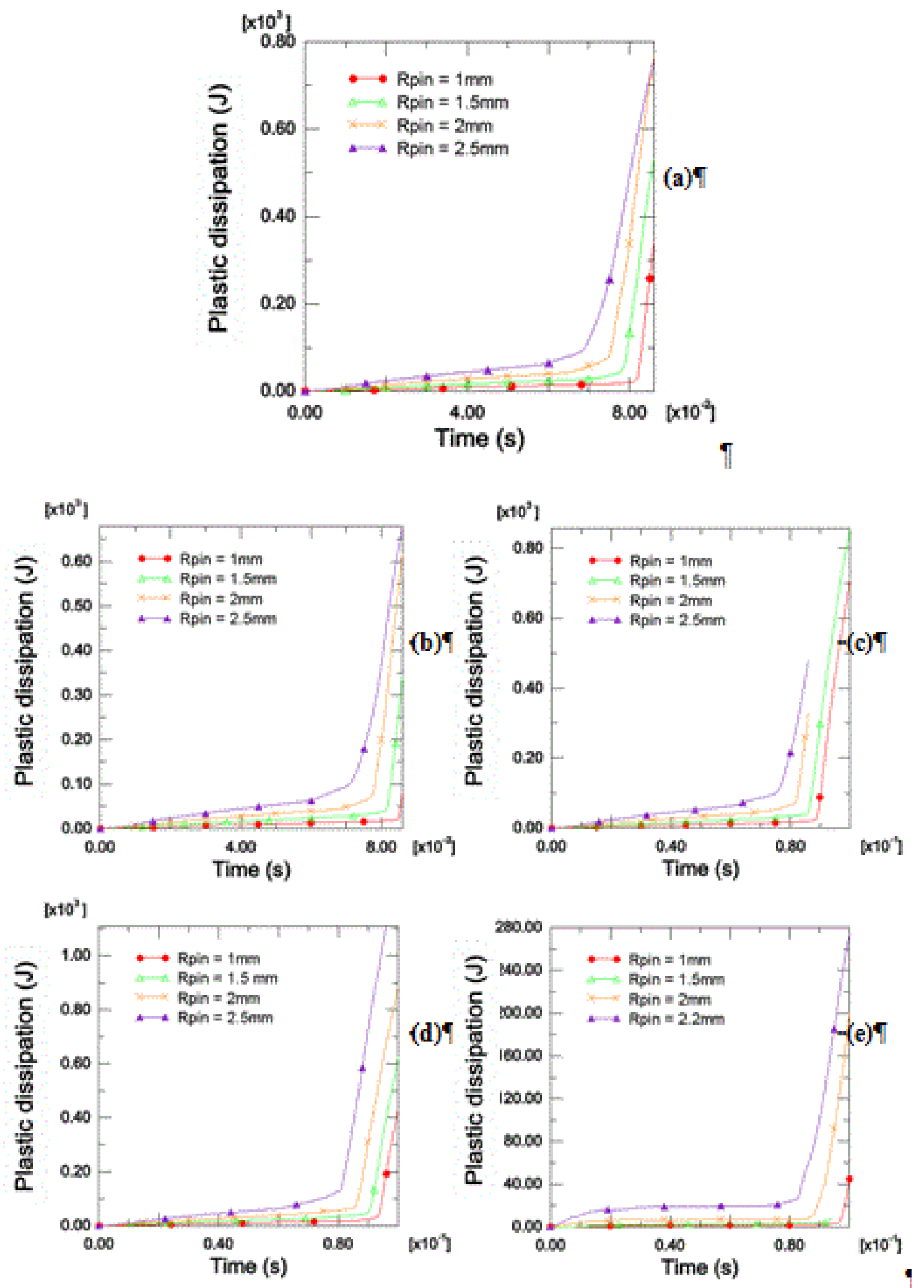

Figure 18 Plots of plastic dissipation against time in plunge stage, (a) $\alpha_{\text {tool }}=0^{\circ}$, (b) $\alpha_{\text {tool }}$ $=2^{\circ}$, (c) $\alpha_{\text {tool }}=5^{\circ}$, (d) $\alpha_{\text {tool }}=8^{\circ}$, (e) $\alpha_{\text {tool }}=10^{\circ}$ : for $R_{\text {pin }}=1,1.5,2$ and $2.5 \mathrm{~mm}$. 


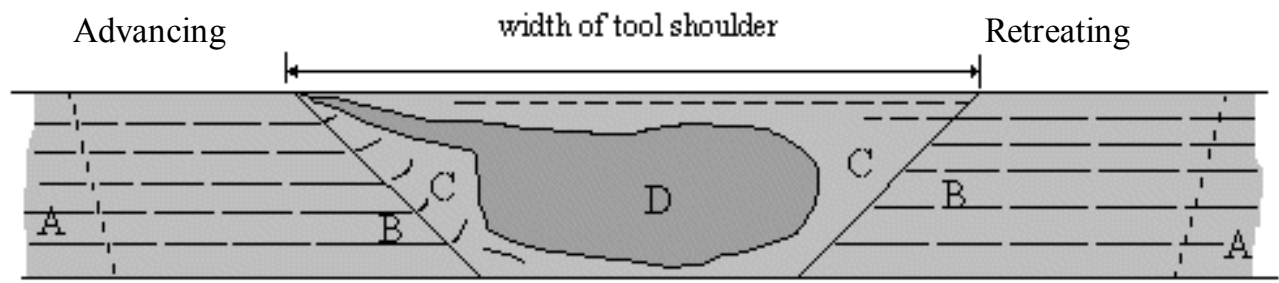

Figure 19 Microstructure classification of friction stir welds [15]. 

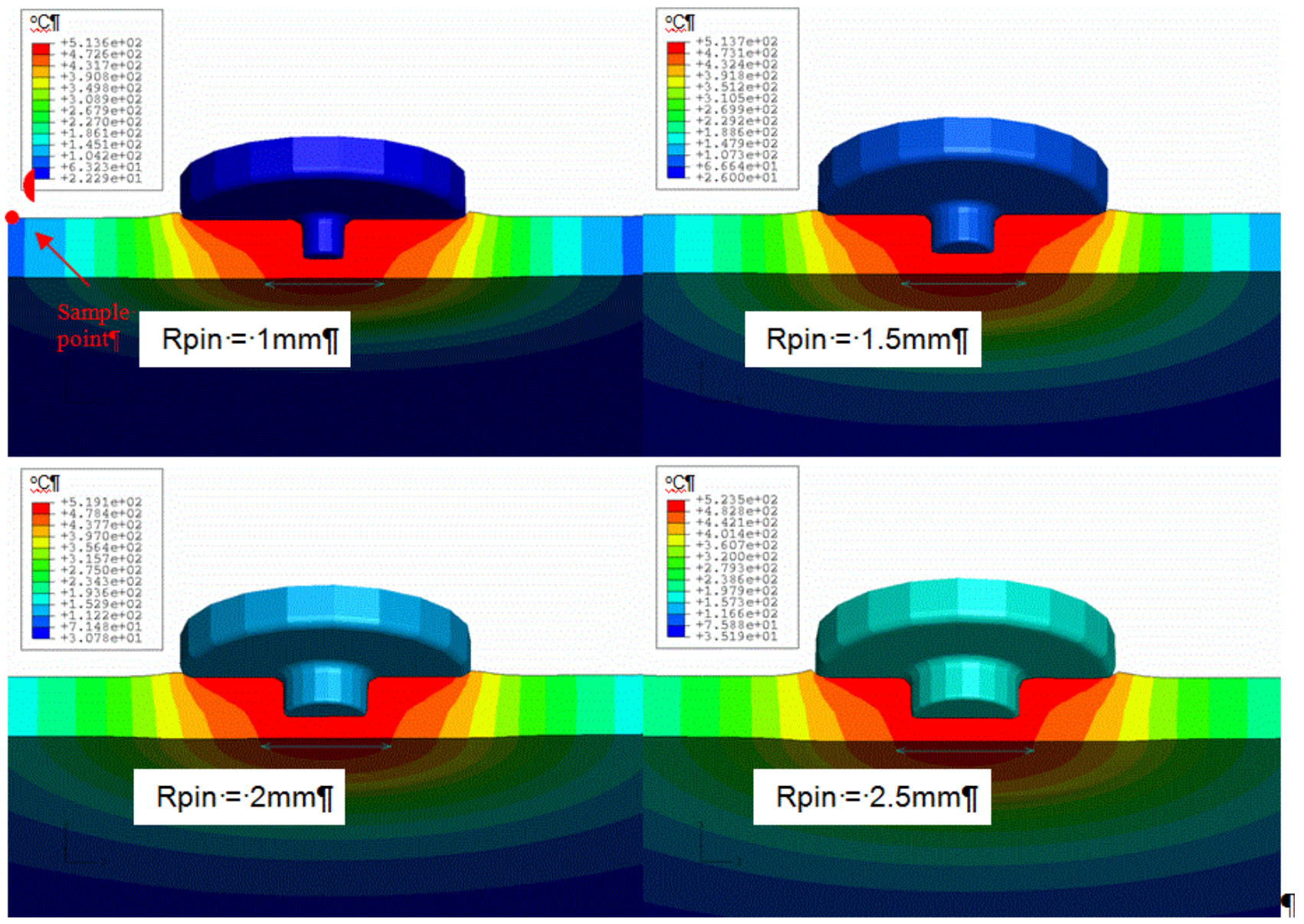

Figure 20 Temperature distributions around the tools with $\alpha_{\text {tool }}=0^{\circ}$, when full contact forms in the plunge stage. 